DR KATE ELLACOTT (Orcid ID : 0000-0001-5261-7465)

Article type : Review Article

\title{
Astrocytes in neuroendocrine systems: An overview
}

Alastair J. MacDonald, Josephine L. Robb, Nicole A. Morrissey, Craig Beall and Kate L.J. Ellacott*

Neuroendocrine Research Group,

Institute of Biomedical \& Clinical Sciences,

University of Exeter Medical School,

Exeter

UK

*Corresponding author

Email: k.ellacott@exeter.ac.uk

Short title: Astrocytes in neuroendocrine systems

Keywords: astrocyte, metabolism, hypothalamus, reproduction, stress, circadian

\section{Abstract}

A class of glial cell, astrocytes are highly abundant in the CNS. In addition to maintaining tissue homeostasis, astrocytes regulate neuronal communication and synaptic plasticity. There is an ever-increasing appreciation that astrocytes are involved in the regulation of physiology and behaviour in normal and pathological states, including within neuroendocrine systems. Indeed, astrocytes are direct targets of hormone action in the CNS, via receptors expressed on their surface, and are also a source of regulatory neuropeptides, neurotransmitters, and gliotransmitters. Furthermore, as part of the This article has been accepted for publication and undergone full peer review but has not been through the copyediting, typesetting, pagination and proofreading process, which may lead to differences between this version and the Version of Record. Please cite this article as doi: $10.1111 /$ jne. 12726

This article is protected by copyright. All rights reserved. 
neurovascular unit, astrocytes can regulate hormone entry into the CNS. This review is intended to provide an overview of how astrocytes are impacted by and contribute to the regulation of a diverse range of neuroendocrine systems: energy homeostasis and metabolism, reproduction, fluid homeostasis, the stress response, and circadian rhythms.

Astrocytes are a type of glial cell abundant in the central nervous system (CNS). Although historically known for their role in maintaining tissue homeostasis, there is a growing recognition that astrocytes actively contribute to the regulation of physiology and behaviour via modulation of neuronal circuits. The goal of this review is to provide an overview of the emerging contribution of astrocytes in neuroendocrine function, highlighting other recent in-depth reviews and key studies for those wishing to explore specific areas further. Related to astrocytes, tanycytes are a specialised glial-cell type lining the base of the third ventricle in the hypothalamus. While our understanding of the importance of tanycytes in neuroendocrine function is evolving, in the interest of focus they will not feature in this article and we refer the readers to other recent reviews in this area $(1,2)$. Although the pituitary gland contains glial cells with morphological similarities to astrocytes, namely pituicytes (3), these will not feature in this review.

\section{An overview of astrocyte function}

Astrocytes are found throughout the CNS, but the ratio of astrocytes to neurons varies depending on the brain region. For a comprehensive overview of the cellular physiology of astrocytes we refer the readers to the recent review by Verkhratsky and Nedergaard (4). Astrocytes utilise variations in intracellular $\mathrm{Ca}^{2+}$ as their main ionic signalling modality and, in contrast to neurons, are not directly electrically excitable.

Astrocytes regulate tissue homeostasis within the brain including supplying energy substrates to neurons, maintaining $\mathrm{pH}$ and ionic balance. Importantly, they also functionally modulate neuronal activity in several ways (4): 1) regulation of ion and neurotransmitter availability (via modulating synthesis, uptake, and recycling); 2) releasing gliotransmitters such as ATP/adenosine, lactate and D-serine; 3) modulating blood brain barrier (BBB)

This article is protected by copyright. All rights reserved. 
permeability and thus controlling entrance and efflux of substances to/from the brain; 4) providing a plastic physical barrier to extra-synaptic neuronal communication through ensheathment of synapses, and 5) regulating synaptic stability. Additionally, astrocytes can regulate neuronal growth (5) and the formation and elimination of synapses during brain development (6-9).

\section{Astrocytes are heterogeneous}

Astrocytes are heterogeneous in both their morphology and function $(10,11)$. These differences can be seen both between and within different regions of the brain. Astrocyte heterogeneity arises partly during development (12); however, plasticity allows astrocytes to change in both form and function in response to physiological and pathological changes within the brain, including in response to aging (13). For example, during brain damage and neurological disease, astrocytes undergo morphological and functional changes termed reactive astrogliosis (14). This process has many roles in neuropathology: forming "glialscars" which separate healthy and diseased tissue (15), enabling phagocytic activity in astrocytes (16), and stimulating astrocytes to become mediators which regulate immune cell recruitment in the CNS (15).

Transcriptional analyses indicate that neurodegenerative diseases and aging are characterised by the formation of "A1-like" reactive neuroinflammatory astrocytes, which have lost neurotrophic capacity and instead contribute to death of neurons and oligodendrocytes via release of toxic factors $(17,18)$. In contrast, ischemic injury is characterised by a predominance of an "A2-like" phenotype amongst the reactive astrocytes, in which astrocyte expression of genes which promote neuronal growth, survival, and synapse repair are increased (19). Understanding astrocyte heterogeneity and the creation of functional classifications is an evolving area and, as is the case with peripheral immune cells (20), phenotypes are likely to be on a plastic continuum depending on variations in microenvironmental conditions within the CNS.

This article is protected by copyright. All rights reserved. 
Glial-fibrillary acidic protein (GFAP) is an intermediate filament protein and commonly used cellular marker astrocytes throughout the brain, although it is also expressed in tanycytes and ependymal cells (21). The GFAP is promotor used experimentally to drive targeted genetic-modification of astrocytes in vitro and in vivo. While GFAP levels are increased in reactive astrocytes and it is used histologically to visualise morphological changes in astrogliosis, it is important to note not all astrocytes, including those in the hypothalamus, express detectable levels of GFAP. Indeed, when GFAP-immunoreactivity is used to quantify changes astrocyte number in response to different experimental or physiological manipulations, it is not necessarily clear whether additional numbers of GFAPimmunoreactive cells reflect astrocyte proliferation or the rise of detectable levels of GFAP pre-existing astrocytes. Other frequently used markers of astrocytes include GLAST, GLT-1 and S100B, although the relative specificity of these is age and brain region specific. Aldehyde dehydrogenase 1 family member L1 (Aldh1L1) is emerging as a specific panastrocyte marker (22) and the Aldh1L1 promotor is increasingly being used to facilitate genetic modification of astrocytes. Moving forward, use of both GFAP and Aldh1L1 expression (gene and protein) will give a more holistic picture of astrocyte form and function than assessment of GFAP levels alone.

The remainder of this review will be focused on evidence for astrocytic involvement in neuroendocrine regulation, largely focusing on hypothalamic astrocytes, but touching on astrocytes in other brain regions where pertinent information is available.

\section{Astrocytes are key players in neuroendocrine regulation}

Astrocytes are direct targets of hormone action via receptors expressed on their surface. As such, hormones can impact astrocyte morphology and function including regulating neurotransmitter availability, and release of gliotransmitters and active metabolic intermediates, which can in turn influence neuronal communication. Astrocytes are also a source of bioactive signalling molecules in the brain: neuropeptides, neurosteroids, and hormones (via direct synthesis or processing of precursors, by enzymes such as deiodinase

2, following their uptake into astrocytes by specific transporters). As part of the

This article is protected by copyright. All rights reserved. 
neurovascular unit, astrocytes can also directly influence BBB permeability and thereby may regulate entrance and efflux of hormones, and other key neuroendocrine modulators such as nutrients and cytokines, from the brain (23). A summary of the proposed mechanisms by which astrocytes regulate the activity of neuroendocrine systems is illustrated in Figure 1.

Astrocytes impact the activity of a variety of neuroendocrine systems, introduced individually below.

\section{Astrocytes and the neuroendocrine regulation of energy homeostasis and metabolism}

\section{Food intake and body weight}

The study of astrocytes in the central control of energy homeostasis has been a growing field in recent years. The discovery that consumption of a high-fat diet increases mRNA for known inflammatory molecules in the rat hypothalamus drew attention to hypothalamic inflammation as an area of study (24). Within the hypothalamus nuclear factor kappa B (NF$\mathrm{KB}$ ) is activated in diet-induced obesity (DIO) and virally-mediated genetic activation of IKK a kinase known to activate NF-kB, in the mouse hypothalamus is sufficient to induce insulin and leptin resistance (25). Moreover, DIO increases glial-fibrillary acidic protein (GFAP; a commonly used marker of astrocytes) gene expression and astrocytic ensheathment of proopiomelanocortin neurons (POMC) in the arcuate nucleus (ARC), consequently decreasing the number of synaptic inputs to POMC neurons; thus, reducing neural activity critical for the inhibition of food intake (26). Following this seminal study, other groups have demonstrated that DIO in rodents is accompanied by an increase in GFAP expression (both at the gene and protein level) and altered morphology of astrocytes in the ARC and other hypothalamic nuclei $(27,28)$. This astrogliosis is also seen in melanocortin-4 receptor deficient mice, which become obese on standard chow diet, due to excess intake (27), suggesting that the gliosis can occur because of obesity in the absence of high-fat diet consumption. Returning DIO mice to a standard chow diet results in weight loss and reversal of the astrogliosis (29), highlighting the plastic nature of this response. The physiological significance of these changes is reinforced by studies indicating that inducing inflammatory signalling in astrocytes results in obesity, while preventing inflammation preserves astrocytic plasticity protecting against DIO (30). Supporting this supposition, brain-wide

This article is protected by copyright. All rights reserved. 
deletion of astrocyte $\mathrm{IKK}_{\beta}$ during the induction of DIO is protective against hypothalamic inflammation and prevents subsequent weight gain (31). While supportive evidence for obesity-associated glial changes from human studies is limited, there is a positive correlation between body mass index and signatures of hypothalamic gliosis, measured by hyper-intensity in magnetic resonance imaging scans (28). Together, these studies implicate astrocyte inflammatory processes, plausibly initiated by $\mathrm{IKK}_{\beta}$, in the development and maintenance of DIO possibly via a loss of astrocyte structural plasticity.

The response of hypothalamic astrocytes in rodents to a high-fat diet appears to be biphasic: there is an initial increase in expression GFAP and pro-inflammatory markers during the first $24-72 \mathrm{~h}$ on a high-fat diet, which then transiently subsides before returning after 14 days on the diet $(28,32,33)$. The first phase of astrocyte activation may occur independently of leptin resistance (32). Inhibition of astrocyte NF-kB mediated inflammatory signalling during the initial phase of high-fat diet-induced astrogliosis abolishes changes in GFAP expression and augments high-fat diet-induced binge eating in mice (33). This has led to the suggestion that the initial phase of astrogliosis is partly a homeostatic or allostatic physiological response to maintain energy balance while the second inflammatory phase is a pathophysiological manifestation of prolonged deviation from energy homeostasis. Further evidence for a role of astrocytes in the physiological response to energy imbalance comes from experiments where mice are pushed out of homeostasis into negative energy balance by fasting. In common with acute energy excess associated with feeding a high-fat diet, fasting impacts hypothalamic astrocyte signalling $(30,34,35)$. Together these studies indicate that hypothalamic astrocytes are sensitive to acute deviations in energy homeostasis.

Astrocytes can directly sense and respond to appetite-modulating hormones via receptors expressed on their surface. Astrocytes neighbouring the third ventricle (3V) that are sensitive to peripheral cues express leptin receptors (36). Diet-induced and genetic obesity increases the number of leptin receptor-expressing astrocytes in the ARC and dorsomedial nucleus $(D M N)$ of the hypothalamus $(37,38)$. Functional studies indicate that chronic (14

This article is protected by copyright. All rights reserved. 
day) intracerebroventricular (ICV) delivery of exogenous leptin increases hypothalamic expression of GFAP and vimentin and increases astrocyte process length. The same treatment reduces expression of synaptic proteins, suggesting increased glial ensheathment of neurons obstructing synapse formation, which may impair integration of feeding cues by these neurons (39). ICV delivery of leptin for 14 days also decreases the expression of astrocyte glucose and glutamate transporters in the hypothalamus, possibly leading to elevated synaptic glutamate (35). A study utilising a mouse model where leptin receptors were selectively deleted from astrocytes in adult mice revealed reduced ensheathment of ARC neurons by astrocytes lacking the leptin receptor (40). In accordance with this, these mice showed reduced sensitivity to leptin and increased sensitivity to ghrelin. These results suggest leptin receptors on astrocytes are crucial for anatomical wiring of the ARC melanocortin circuits critical for the regulation of energy homeostasis and that this wiring ensures appropriate responses to endocrine signals that modulate food intake. A second mouse model with developmental astrocyte-specific deletion of leptin receptors showed an increased body-weight and fat-mass gain on a high fat diet, accompanied by greater hypothalamic leptin resistance and increased gliosis compared with wild-type controls (41). Astrocyte sensing of leptin also appears to be critical during hypothalamic development (42).

Like leptin, ICV treatment with the orexigenic hormone ghrelin regulates the expression of a number of proteins expressed by hypothalamic astrocytes including structural proteins (GFAP and vimentin) and transporters (glucose and glutamate transporters) (43). In vitro primary mouse astrocytes, primary rat astrocytes and the C6 astrocytoma cell line are responsive to ghrelin, while glia cultured from mice lacking the growth-hormone secretagogue receptor 1A (GHSR-1A) do not, suggesting some of the effects of ghrelin may be due to direct activation of astrocyte GHSR-1A (43-45). This is supported by immunohistochemistry which has identified GHSR-1A co-localised with GFAP in the rat hypothalamus (43). Together these studies provide evidence that astrocytes are direct sensors of endocrine signals regulating energy balance, and likely mediate, at least in part, some of the physiological effects of these hormones in the CNS.

This article is protected by copyright. All rights reserved. 
The application of opto- and chemo-genetic technologies for manipulation of ARC astrocyte signalling has provided conflicting results with respect to astrocytic regulation of feeding behaviour. In 2015, Yang and colleagues reported that chemogenetic activation of $\mathrm{Ca}^{2+}$ signalling in ARC astrocytes caused a decrease in both nocturnal feeding and ghrelininduced food intake while enhancing the satiating effect of leptin. Their work suggests this was mediated by astrocyte-derived adenosine inhibiting agouti-related peptide (AgRP) neurons via activation of pre-synaptic adenosine A1 receptors (46). This was supported by follow-up study from the same group, which showed that optogenetic-mediated activation ARC astrocyte signalling reduced food intake (47). However, in contrast a second independent research group, employing a similar chemogenetic methodology, found that activating $\mathrm{Ca}^{2+}$ signalling hypothalamic astrocytes increased food intake during the dark phase by excitation of AgRP neurons (34). The discrepancies in these results may be due to technical differences (e.g. injection of virus, dose of chemogenetic ligand) or may represent a state-dependent effect of astrocyte activation on feeding behaviour. As such, much remains to be learnt about the contribution of astrocytes to hypothalamic control of feeding.

Although not as widely studied in this context, astrocytes outside the hypothalamus may also play a role in regulating food intake given that they can control some consummatory behaviours. For example, activation of nucleus accumbens (NAc) core astrocytes reduces the self-administration of cocaine after reinstatement via an increase in synaptic glutamate (48). The process of cocaine self-administration and extinction appears to render NAc core astrocytes hypoactive, suggesting they play a role in addiction (49). Given that NAc neurons are thought to be involved in driving the motivation to feed (50), astrocyte regulation of transmission in this circuit may alter feeding, although this remains to be investigated. A second population of extra-hypothalamic astrocytes shown to influence food intake are those in the nucleus of the solitary tract (NTS). NTS astrocytes appear to play a role in glucagon-like peptide (GLP-1) mediated-satiety since these cells show increases in intracellular $\mathrm{Ca}^{2+}$ in response to the GLP-1 receptor agonist exendin-4 in an ex vivo rat brain slice. In rats, delivery of exendin-4 to the NTS reduces food intake, an effect that is abolished by pre-treatment with the astrocyte metabolic inhibitor fluorocitrate (51). The exact

This article is protected by copyright. All rights reserved. 
mechanism for this effect remains unclear as GLP-1 receptors were not observed on astrocytes in mice expressing green fluorescent protein in GLP-1 receptor containing cells (52).

To conclude, astrocytes in the hypothalamus are responsive to short-term and prolonged deviations in energy homeostasis. These cells can directly sense appetite-regulating hormones and adjust morphology, expression of transporters, and potentially release of gliotransmitters accordingly, to alter the firing of neurons that control food intake. Extrahypothalamic astrocytes may play a role in food intake which will be an emerging area for future research. A schematic summary of the current understanding of how astrocytes may impact feeding behaviour can be found in Figure 2.

\section{Glucose homeostasis}

Glycaemia regulation is largely controlled by the pancreas, principally by glucose-dependent insulin secretion from pancreatic $\beta$-cells through $\mathrm{Ca}^{2+}$ dependent exocytosis ${ }^{1}$. In health, insulin secretion is largely sufficient to control blood glucose within the healthy range (4$7 \mathrm{mM}$ glucose). When $\beta$-cells are compromised, such as in type 1 diabetes, or when insulin action is insufficient to adequately control glucose levels, such as during early type 2 diabetes, other tissues, such as the brain, play a more prominent role.

In the CNS, blood glucose is mainly regulated by the hypothalamus, with the hindbrain also playing an important role. POMC, AgRP, and neuropeptide $Y$ (NPY) neurons of the ARC and steroidogenic factor-1 (SF-1) neurons of the ventromedial nucleus of the hypothalamus (VMN) all modulate glucose homeostasis through regulation of food intake and pancreatic hormone release (53-55).

This article is protected by copyright. All rights reserved. 
Given that astrocytes are near the cerebral blood supply and directly interact with pericytes which regulate vascular tone, it is likely that astrocytes detect changes in glucose levels before neurons. Over the past decade several studies have demonstrated that astrocytes detect changes in glucose availability, and direct manipulation of astrocyte function alters glycaemia and/or glucose tolerance. For example, glucose insufficiency induced by 2deoxyglucose (2-DG) increases intracellular $\mathrm{Ca}^{2+}$ in hindbrain astrocytes (56). This astrocyte activation is required for the stimulation of adjacent catecholamine neurons, indicating that astrocytes couple glucose availability to neuronal activation (56). Catecholamine neurons stimulate the release of adrenaline, contributing to the counterregulatory response (CRR) to hypoglycaemia, suggesting astrocytes play a role in the CRR. Rats exposed to three days of recurrent insulin-induced hypoglycaemia have reduced hypothalamic expression of the main astrocytic glutamate transporter GLT-1. This correlates with reduced glutamate uptake in primary cultured rat astrocytes, and to glutamatergic neurotransmission failure in vivo, attenuating activation of the CRR (57). Further supporting an astrocytic role in full activation of the CRR to hypoglycaemia, loss of the brain glucose transporter GLUT2 causes loss of the glucagon response to hypoglycaemia in mice. Rescue of GLUT2 levels specifically in GFAPexpressing astrocytes is sufficient to restore the glucagon response to hypoglycaemia, suggesting that astrocytic glucose sensing is essential to maintaining glucose homeostasis (58). In addition, stimulation of the CRR following fourth ventricular (4V) administration of 2-DG is ablated following pre-treatment with glial metabolic inhibitor fluorocitrate, indicating that astrocytes neighbouring the $4 \mathrm{~V}$ are also required for activation of the CRR. These data suggest changes in hypothalamic and hindbrain astrocyte function are required for full activation of the CRR to hypoglycaemia.

In addition to astrocytic GLUT2 restoring the CRR as discussed above, there is further evidence that astrocyte function is directly regulated by glucose availability. Insulin receptor deletion from hypothalamic astrocytes in mice reduces astrocytic intracellular glucose levels and astrocytic ramification (59), reducing the physical contact between neurons and astrocytes. Sensitivity to changes in glucose availability and subsequent communication of POMC neurons is also reduced. This induces glucose intolerance, likely mediated by reduced brain glucose transporter GLUT1 expression (59). Interestingly, in a separate study, 
overexpression of GLUT1 in GFAP-containing cells was sufficient to rescue diabetic hyperglycaemia induced by STZ (streptozotocin) administration (60). Taken together, these data suggest that increased or decreased glucose delivery into hypothalamic astrocytes (via GLUT1) is key in the central sensing of glucose and subsequent regulation of peripheral glucose levels.

In the CNS glycogen is stored predominantly in astrocytes (61). In astrocytes, as in the periphery, glycogen synthesis is dependent upon insulin receptor activation through the PI3K/Akt pathway to increase intracellular glycogen storage during glucose sufficiency. Although the glycogen content of astrocytes is low compared to liver and skeletal muscle, it is biologically meaningful. Glycogen breakdown by glycogenolysis is required to sustain neural activity during glucose deprivation (62). Moreover, astrocytic glycogen supercompensation is postulated to contribute to CRR failure following recurrent hypoglycaemia. For example, in mice hypothalamic glycogen content doubles in response to repeated once daily brain injection of 2-DG to simulate recurrent hypoglycaemia (63). On recovery from insulin-induced hypoglycaemia in mice, brain glycogen content has been reported to increase by $25 \%$ over basal levels, suggesting short term glycogen supercompensation. This may be a species-specific phenomenon as little or no glycogen supercompensation has been described in rat hypothalamus after hypoglycaemia (64). However, some glycogen supercompensation has been observed in cortex, striatum and hippocampus following acute hypoglycaemia in rats (65). Whether glycogen supercompensation following acute/recurrent hypoglycaemia occurs in humans with diabetes remains uncertain (66).

In both STZ-induced diabetes and the non-obese diabetic (NOD) mouse models increased hippocampal astrogliosis has been observed reflected in both increased number of GFAPimmunoreactive cells and increased cellular area (67). Conversely, in rats with poorlycontrolled diabetes (STZ-induced) the number of hypothalamic GFAP-immunoreactive cells decreased within 6 weeks of poor glucose control, likely mediated by increased astrocytic cell death $(68,69)$. As discussed above, in humans and in rodent models, obesity which is often concurrent with elevated glucose levels, also causes hypothalamic gliosis and inflammation (28).

This article is protected by copyright. All rights reserved. 
Glucose intolerance driven by high-fat diet challenge also has an astrocytic component. For example, astrocyte-specific inducible knockout of the NF-KB activating molecule IKK $\beta$ improves glucose intolerance caused by DIO, restoring glucose handling and insulin sensitivity in addition to reducing astrogliosis in the medial basal hypothalamus/ARC (30). Additionally, astrocyte-specific constitutive activation of $\mathrm{IKK}_{\beta}$ causes glucose intolerance in chow fed mice through a mechanism involving increased extracellular GABA preventing the release of the growth hormone brain derived neurotrophic factor (BDNF) (30). Together these data suggest that inflammatory astrogliosis mediated by the NF-KB transcription factor dysregulates glucose homeostasis through increased GABA and reduced BDNF release.

In summary, astrocytes play a crucial role in maintaining glucose homeostasis by regulating the hypoglycaemic CRR through direct glucose sensing and conversely synthesising and storing glycogen when sufficient glucose is available. Beyond this, astrocytes activate neuronal networks implicated in endocrine glucose regulation through NF-kB activation, and glutamate and GABA signalling in direct response to availability of glucose, insulin and glucagon. A schematic of the current understanding of how astrocytes may impact systemic glucose homeostasis can be found in Figure 3.

\section{Thyroid hormone axis}

The hypothalamic-pituitary-thyroid (HPT) axis is a key neuroendocrine feedback system regulating growth, development, and metabolism, which when impaired also impacts reproductive capacity and cognition. Thyrotropin releasing hormone (TRH) neurons in the hypothalamus project to the anterior pituitary thyrotropes and stimulate the release of thyrotropin/thyroid stimulating hormone (TSH) which in turn stimulates thyroxine (T4), and to a lesser degree 3,3',5-triiodothyronine (T3), from the thyroid gland. Plasma T4 and T3, and T3 locally produced in the brain, provide negative feedback regulating the production of TRH and TSH. Limited evidence, largely from in vitro studies, suggests that astrocytes may be direct targets of action of TRH via receptors expressed on their surface (70-72) but the physiological relevance of this remains unclear.

This article is protected by copyright. All rights reserved. 
Astrocytes express a variety of thyroid hormone transporters (73). Whether these cells actively participate in transport of thyroid hormones into the brain across the BBB is uncertain (74), but once in the CNS, thyroid hormones are taken up into astrocytes and tanycytes which mediate local conversion of T4 to T3 by type-2 deiodinase 2 (D2) $(75,76)$. The half-life of D2 is regulated by the presence of T4: when T4 levels are low the half-life of D2 is increased and vice versa (77). However, within the hypothalamus T4-induced D2 regulation is minimal and D2 activity is preserved even when T4 levels are high, enabling the hypothalamus to maintain higher sensitivity to T4 (78). Within the hypothalamus, endocrine action of plasma T3 and paracrine action of locally produced T3 on TRH neurons are part of the negative feedback loop which inhibits HPT axis activity. In mice, genetically mediated germ-line deletion of the deiodinase 2 gene (DIO2) specifically from GFAP-expressing cells (encompassing a population of astrocytes) reduces D2 activity in the cortex, hippocampus and cerebellum, but not the hypothalamus indicating that tanycytic D2 and not astrocytic D2 is likely responsible for mediating T4 to T3 conversion within this brain region (79). This was further supported by the fact that loss of D2 in GFAP-expressing cells did not result in HPT-axis dysfunction or alterations in the morphology of the thyroid. However, despite no overt changes in growth curves, body composition or feeding behaviour, these animals show subtle changes in whole body metabolism consistent with changes in substrate utilization suggesting a contribution of D2-generated T3 in the brain, mostly likely the hypothalamus and/or brainstem, in influencing systemic energy homeostasis (80).

Astrocyte function is directly modulated by thyroid hormones, which in turn can modulate neuronal activity. Exposure of primary human astrocytes in culture to T3 stimulates fattyacid oxidation and ATP production (81). Neurotrophin-3 and basic fibroblast growth factor (FGF-2) have been implicated as factors released from astrocytes in response to T3 which impact neuronal activity (82). In addition to modulating gliotransmitter release, in vitro studies demonstrate that T3 enhances glutamate uptake into astrocytes by increasing the activity of astrocyte glutamate transporters GLT-1 and GLAST (83), which could in turn impact communication between neurons by altering the glutamate availability in the synaptic cleft. Together these data suggest that in addition to contributing to controlling thyroid hormone signalling in the brain by regulating local T3 levels, autocrine or paracrine activity of T3 on astrocytes in the CNS may modulate neuronal communication.

This article is protected by copyright. All rights reserved. 
It remains to be determined whether astrocytes form part of the negative feedback loop that regulates HPT-axis function by modulating activity of TRH neurons. Furthermore, it is unclear how the effects of T3 on astrocyte activity are mediated, as the presence of thyroid hormone receptors in astrocytes is controversial (84) so more work is needed in this area.

\section{Astrocytes and the neuroendocrine regulation of reproductive function}

\section{Hypothalamic-pituitary-gonadal (HPG) axis}

Sitting at the top of the hypothalamic-pituitary-gonadal (HPG) axis, gonadotropin releasing hormone ( $\mathrm{GnRH}$; also known as luteinising hormone releasing hormone [LHRH]) neurons are master regulators of the neuroendocrine control of reproduction. GnRH-secreting neurons originate in the nasal placode. During prenatal development their cell bodies migrate to the hypothalamic preoptic area (POA) and organum vasculosum laminae terminalis (OVLT). $\mathrm{GnRH}$ neurons project to the median eminence where they secrete $\mathrm{GnRH}$ into the hypophyseal portal circulation. GnRH acts at receptors on gonadotroph cells in the pituitary which secrete luteinising hormone (LH) or follicle stimulating hormone (FSH) depending on the pulsatile pattern of $\mathrm{GnRH}$ release. Appropriate pulsatile release of these hormones is essential for the initiation and maintenance of reproductive function. These hormones act on the gonads which in turn release their own hormones which provide negative feedback to the hypothalamus, completing the axis.

Synchronised GnRH neuronal firing has been seen in vitro and is proposed to be essential for the pulsatile $\mathrm{GnRH}$ secretion required for $\mathrm{LH}$ release (85). In vivo, GnRH neurons are intermingled with other hypothalamic cells and therefore direct gap junctional connection between neighbouring $\mathrm{GnRH}$ neurons is unlikely. This raises the possibility that perhaps synchrony arises from gap junctions between $\mathrm{GnRH}$ neurons and astrocytes, which have been reported to be formed of connexin (Cx) 43, 26 and 32 proteins (86). Indeed, oestrogen and/or progesterone administration increases the amount of $\mathrm{Cx} 43$ in the POA of female but not male rats suggesting sexually dimorphic function of astrocyte gap junctions (87). The premise that astrocytes may be key players in the coordination of GnRH neuron synchrony is

This article is protected by copyright. All rights reserved. 
supported by recent data indicating that GFAP, Cx43 and GnRH closely associate in the mouse median eminence. In addition, in cultured embryonic mouse nasal placode explants, pharmacological Cx43 gap junction blockade reduces both $\mathrm{GnRH}$ neuron synchronicity and $\mathrm{GnRH}$ secretion (88). Furthermore, female $\mathrm{Cx} 43+/-$ mice show altered reproductive behaviour and disrupted oestrus cycles, providing indirect in vivo evidence for a potential role of astrocyte-neuronal communication in the regulation of reproductive function (87).

In addition to connexins, other mediators of neural cell interaction have been implicated in regulating activity of GnRH neurons. Polysialylated neural cell adhesion molecule (PSANCAM) promotes cell movement by hindering cell adhesion and has been investigated in relation to the structural plasticity of GnRH neurons. Removing the PSA from NCAM in the median eminence of cycling female rats appears to alter the structural interaction between astrocytes (GFAP-immunoreactivity) and GnRH neurons (GnRH-immunoreactivity) (89); however, this study did not report any disruption of the oestrus cycle in these mice, so the physiological impact remains unclear. Another adhesion-related protein expressed by hypothalamic astrocytes is receptor-like protein tyrosine phosphatase $\beta$ (RPTP- $\beta$ ), a receptor which adheres to the cell adhesion molecule contactin (90). RPTP- $\beta$ expression increases in the hypothalamus of female mice immediately prior to puberty suggesting a role for contactin (GnRH neurons) to RPTP- $\beta$ (astrocytes) adhesion in structural plasticity (90). A further adhesion molecule, namely synaptic cell adhesion molecule 1 (SynCAM1), has been implicated in structural plasticity relating to reproductive function. This protein is found in $\mathrm{GnRH}$ neurons and hypothalamic astrocytes. The adhesive activity and expression of SynCAM1 in hypothalamic astrocytes is positively regulated by epidermal growth factor B4 (erbB4) receptor signalling $(91,92)$. Female mice engineered to express a dominantnegative form of SynCAM-1 in astrocytes exhibit delayed vaginal opening and first oestrus, reduced litter size and a disrupted oestrus cycle (91). This suggests astrocytic SynCAM1 mediated structural plasticity is critical for correct reproductive function. Importantly, immunofluorescence and electron microscopy of post-mortem human female brain tissue shows that the close anatomical association between $\mathrm{GnRH}$ neurons and astrocytes is preserved across species (93).

This article is protected by copyright. All rights reserved. 
In support of a potential role for astrocytes in the regulation of the neuroendocrine control of reproduction, astrocytes are directly responsive to changes in the reproductive cycle. Astrocytes cultured from rat hypothalami express oestrogen receptors and show an increase in intracellular $\mathrm{Ca}^{2+}$ and progesterone synthesis in response to oestradiol suggesting they may be involved in integrating hormonal feedback from the gonads (94). Astrocytes in the OVLT and POA of young female rats show diurnal changes in morphology on proestrus (the first day of the rodent oestrus cycle); a phenomenon exclusively seen in astrocytes that closely appose GnRH neurons (95). Astrocytes express VAPC2 (Vasoactive intestinal peptide receptor 2), and the diurnal component of these morphological changes is lost when vasoactive intestinal peptide (VIP) is knocked down from the suprachiasmatic nucleus (96). While the function of these changes in astrocyte morphology is not yet clear, it suggests they may be critical in regulating the ability of GnRH neurons to stimulate the proestrus LH surge.

As well as enabling structural reorganisation of neurons, astrocytes can modulate neuronal function by the release of gliotransmitters. One gliotransmitter identified to act on $\mathrm{GnRH}$ neurons is prostaglandin E2 (PGE2) (97). PGE2 directly increases the firing rate of GnRH neurons in mice regardless of sex or oestrus stage, an effect blocked by a prostaglandin E2 receptor 2 (EP2R) antagonist. Furthermore, inhibition of astrocytes with the metabolic inhibitor fluorocitrate decreases spontaneous $\mathrm{GnRH}$ neuron firing without reducing the response to exogenous PGE2, suggesting astrocytes are the source of PGE2 (98). Neuregulin (NRG) induces PGE2 release via activation of astroglial epidermal growth factor B4 (erbB4) receptors which may promote $\mathrm{GnRH}$ secretion. In vivo expression of dominant-negative erbB4 receptors in mouse astrocytes (GFAP-DN-erbB4 mice) attenuates the infantile LH surge and delays the onset of puberty in female mice (99). ErbB4-meditated PGE2 release from astrocytes provides excitatory drive to $\mathrm{GnRH}$ neurons which may explain the effects of deletion on reproduction (98). Expression of a mutant epidermal growth factor B1 (erbB1) receptor in astrocytes whose intracellular domain is non-functional also causes reproductive dysfunction: irregular oestrus cycles and a reduced proestrus LH surge (100), but it is unclear if this effect is due to decreased PGE2 release. Oxytocin, a hormone critical for the initiation of female puberty, acts at oxytocin receptors on hypothalamic astrocytes to stimulate PGE2

This article is protected by copyright. All rights reserved. 
release and subsequent GnRH secretion (101). A second hormone, namely insulin, also acts directly on astrocytes and deletion of insulin receptors from astrocytes causes reproductive dysfunction in mice. Astrocytes in these animals show lower levels of PGE2 than wild-type controls suggesting insulin acts on hypothalamic astrocytes to stimulate GnRH neurons via PGE2 gliotransmission (102). PGE2 also negatively regulates synaptic input to GnRH neurons in an activity dependent manner suggesting astrocytes can decrease GnRH neuronal firing (103). Taken together this work shows that PGE2 release from hypothalamic astrocytes downstream of numerous receptors is important for stimulating GnRH neuron activity and, in turn, normal reproductive function.

In addition to active transmitter release, astrocytes appear to play a critical role mediating peripubertal changes in synaptic glutamate recycling. In the hypothalami of first proestrus rats (compared to juvenile rats), the glutamate synthesis enzyme glutamate dehydrogenase $(G D H)$ is increased while the glutamate metabolic enzyme glutamine synthetase (GS) is decreased (104). This suggests that at first proestrus the hypothalamus is biased towards producing more glutamate which may provide excitatory drive to GnRH neurons for the first LH surge.

In summary, astrocytes in the vicinity of $\mathrm{GnRH}$ neurons are indispensable for normal reproductive function since many loss-of-function manipulations result in reproductive deficits. Astrocytes may impact secretion from GnRH neurons by regulating synchronisation via gap junctions, structural remodelling, release of gliotransmitters, and control of glutamate recycling. As such astrocytes can be considered core element of the HPG axis. A schematic summary of the current understanding of how astrocytes may impact the function of the HPG axis can be found in Figure 4.

This article is protected by copyright. All rights reserved. 


\section{Oxytocin neurons}

A second hypothalamic population relevant to neuroendocrine control of reproduction are the magnocellular oxytocin neurons of the supraoptic nucleus (SON). These neurons secrete the hormone oxytocin into the bloodstream to drive lactation and parturition through actions at the breast and uterus respectively. In rats, astrocytes neighbouring oxytocin neurons show a dramatic morphological change, characterised by retraction of processes, during times of high oxytocin secretion such as lactation $(105,106)$. This increases glutamate availability, presumably because astrocyte processes are not nearby to facilitate reuptake (107). This increase in glutamate availability in the synaptic cleft in turn reduces synaptic input to oxytocin neurons by activating presynaptic metabotropic glutamate receptors (mGluRs), which reduce neurotransmitter release (107). This retraction of astrocyte processes also decreases the availability of D-serine, a glial derived co-agonist of the NMDA receptor, thus impairing glutamatergic plasticity (108). However, the essential nature of astrocytic remodelling in the regulation of lactation is questioned by data indicating that inhibiting this glial remodelling by improving cell-cell adhesion in vivo in lactating rats does not produce an abnormal lactation phenotype nor does it disrupt the burst firing of magnocellular neurons characteristic of a lactation signal (109). Thus, astrocytes in apposition to SON oxytocin neurons act to restrict glutamate release and NMDA-receptor activation during lactation, but the functional contribution of these changes remains unclear.

\section{Astrocytes and the neuroendocrine regulation of fluid homeostasis}

Arginine Vasopressin (AVP) maintains fluid homeostasis by binding to vasopressin 2 receptors (V2Rs) in the kidney, increasing reabsorption of water back into the blood. AVP is synthesised and secreted from neurons that are found primarily in the paraventricular (PVN), SON and suprachiasmatic (SCN) nuclei of the hypothalamus (110). Magnocellular PVN AVP neurons project to the posterior pituitary gland where AVP is released into the blood or diffusely from dendrites into the hypothalamus through $\mathrm{Ca}^{2+}$ dependent exocytosis. Parvocellular PVN neurons, which project to the median eminence, also produce AVP and modulate activity of corticotropes in the anterior pituitary, thus contributing to the

This article is protected by copyright. All rights reserved. 
regulation of the hypothalamic-pituitary-adrenal (HPA) axis, which will be discussed in more detail later in this review. AVP is released in response to hyperosmotic stress, with rehydration reducing AVP release. Hypothalamic glutamate concentrations increase during hyperosmotic stress, stimulating SON AVP neurons to fire in a phasic manner leading to AVP release (111-113).

Astrocytes show morphological changes in response to alterations in fluid homeostasis: dehydration reduces GFAP-immunoreactivity in the rodent SON and ventral glial limitans (114-116). Furthermore, in vitro AVP increases astrocytic volume $(117,118)$. In rats, immunoreactivity for c-Fos in the SON, in response to hyperosmotic stress, increases in astrocytes before neurons $(119,120)$, indicating that astrocytes may be early sensors of dehydration. This is further supported by a study indicating that pharmacological blockade of the gap-junction protein Cx43 prevents osmotic activation of neuronal, but not astrocytic c-Fos, whereas the glial metabolic inhibitor fluorocitrate attenuates c-Fos expression in both neurons and astrocytes (120). Together these data support a critical role for astrocytes in the physiological response to changes in osmolarity.

AVP receptors are expressed on astrocytes $(121,122)$. Activation of V1bRs and V3Rs by AVP in primary rodent astrocytes in vitro results in $\mathrm{Ca}^{2+}$ release from intracellular stores, whereas activation of V1aRs leads to increased $\mathrm{Ca}^{2+}$ uptake from the extracellular space (123). Both mechanisms result in increased glutamate release from astrocytes, resulting in increased extracellular glutamate concentration $(122,123)$. Although these studies were conducted in primary rodent astrocytes derived from the cortex and hippocampus, if hypothalamic astrocytes display a similar response, then this increased glutamate availability may be a mechanism by which AVP action on astrocytes modulates neurotransmission.

There is further evidence that astrocytes can impact fluid homeostasis by impacting neuronal firing. In vitro AVP increases monocarboxylate transporter (MCT) expression on primary rat astrocytes, increasing lactate release (124), which may increase availability of

This article is protected by copyright. All rights reserved. 
lactate as a neuronal fuel source; thus, impacting neuronal firing. In the SON, the amino acid taurine is released during hypo-osmotic cell swelling, reducing firing of AVP neurons via direct binding to glycine receptors $(125,126)$. This hypo-osmotic regulation of taurine release in the SON is almost completely blocked by glial metabolic inhibitor fluorocitrate, but not by neurotoxic levels of $\operatorname{NMDA}(126,127)$, suggesting that that this effect is glial dependent. Within the SON there is also evidence to suggest that astrocytes can modulate GABAergic synaptic inputs via endocannabinoid signalling (128).

Intriguingly, within the PVN the orexigenic hormone ghrelin can directly stimulate firing of AVP neurons, inducing release of AVP which in turn induces ATP release from astrocytes. This subsequently impacts PVN AVP neurons by modulating presynaptic excitatory GABAergic inputs on to these cells (129). These data provide evidence of glial modulation of the activity of PVN AVP neurons and a novel link between the regulation of energy and fluid homeostasis.

In addition to AVP pathway, the renin-angiotensin system is another key player in the neuroendocrine control of fluid homeostasis. Angiotensin II (AngII) is synthesised during dehydration and in response low blood pressure and mediating its physiological effects in this system via type-1 angiotensin II receptors ( $\mathrm{AT}_{1}$-Rs) (130). Angll activates neurons in the subfornical organ (SFO), PVN, and SON, to promote hydration and AVP release (131-133). $A T_{1}-\mathrm{R}$ are expressed on both neurons and astrocytes, with both cell types displaying increases $\mathrm{Ca}^{2+}$ signalling in response to Angll treatment $(134,135)$. In rats, AVP release and sodium intake in response to Angll treatment are blocked by the glial metabolic inhibitor fluorocitrate, indicating that glia may play a key role in AngII/AVP signalling (136). Decreased activity of hypothalamic GLT-1, a glutamate transporter selectively expressed in astrocytes, following Angll treatment has been implicated in increasing activity of PVN neurons and enhancing sympathetic outflow (137). Together these data suggest Angll action via on astrocytes may help to re-establish fluid homeostasis after low blood pressure.

This article is protected by copyright. All rights reserved. 
In summary, astrocytes contribute to the regulation of fluid homeostasis via modulation of AVP and renin-angiotensin signalling in the CNS. This appears to be mediated, in part, by direct hormone action on astrocytes. Astrocytes regulate activity of neurons in the PVN and SON by modulating release of gliotransmitters, regulating neurotransmitter availability in the synaptic cleft, and by ensheathment of neurons which is highly plastic dependent on physiological state. A schematic summary of the current understanding of how astrocytes may impact the neuroendocrine regulation of fluid homeostasis can be found in Figure 5.

\section{Astrocytes and the neuroendocrine regulation of the stress response: Hypothalamic- pituitary-adrenal axis}

The hypothalamic-pituitary-adrenal (HPA) axis is a key neuroendocrine feedback loop regulating the organismal response to stress, encompassing both psychological and physiological stressors. Parvocellular corticotropin-releasing hormone (CRH) and AVP neurons in the hypothalamic PVN project to the median eminence; where CRH and vasopressin are released and transported to the anterior pituitary. There they act synergistically to promote secretion of adrenocorticotropin-releasing hormone (ACTH) from corticotropes. ACTH is then taken up into the blood and in turn acts on the adrenal medulla to promote secretion of cortisol (corticosterone in rodents). Cortisol - acting via the glucocorticoid receptor - provides negative feedback inhibition on the production of ACTH and $\mathrm{CRH}$, by acting on corticotropes and parvocellular PVN neurons respectively. Amplification of HPA-axis activity is provided by adrenaline and noradrenaline release from the adrenal gland in response to activation of the sympathetic nervous system.

Astrocytes, in common with a variety of neural cells, express glucocorticoid and mineralocorticoid receptors $(138,139)$ and are direct targets of glucocorticoid action. Recent transcriptional analysis indicates that 381 genes are regulated by dexamethasone treatment (a synthetic glucocorticoid) of primary mouse astrocytes (140). Both acute and chronic treatment of mice with corticosterone causes regulation of astrocyte-associated gene expression, reinforcing evidence from in vitro studies indicating that astrocytes are directly regulated by glucocorticoids. However, in the case of the in vivo studies the impact

This article is protected by copyright. All rights reserved. 
is likely a combination of direct (action on astrocytic-glucocorticoid receptors) and indirect effects (action via glucocorticoid receptors on other neural cells, including neurons, which subsequently impact astrocyte activity) (141).

Functional in vitro and in vivo studies support direct glucocorticoid mediated alterations in astrocyte signalling and morphology. In vitro, glucocorticoid treatment induces rapid increases astrocyte $\mathrm{Ca}^{2+}$ signalling (142) suggestive of an activation of non-genomic pathways downstream of glucocorticoid receptors. Glucocorticoid treatment of astrocytes in culture also enhances neuropeptide (ANP) release from astrocytes, promotes glutamate recycling, and leads to increases in GFAP-immunoreactivity and rearrangement of F-actin fibres, indicative of cellular stress $(143,144)$. In contrast, chronic treatment of primary astrocytes in culture with glucocorticoids reduces cellular proliferation and glucocorticoid receptor expression $(145,146)$. This is recapitulated in an in vivo rodent model where astrocyte number is reduced in the frontal cortex by chronic HPA-axis activation through ACTH administration (145) or in response to chronic corticosterone treatment, with or without additional behavioural stress $(147,148)$. It has been proposed that astrocytes are critical players in the regulation the neurogenesis during stress (149), a phenomenon which may underlie subsequent behavioural adaptations. Importantly, in line with sex differences in the response to stress at the organismal level (150) the response of astrocytes to stress is also sexually dimorphic, which may reflect the intersection of multiple hormonal signalling pathways at the level of the astrocyte (151).

Although not directly studied in this setting, of potential significance for regulation of HPAaxis function, astrocytes are also directly responsive to noradrenaline via receptors expressed on their surface (152). Noradrenaline impacts $\mathrm{Ca}^{2+}$ signalling and cellular metabolism in astrocytes (153-155). Neurophysiological studies indicate that within the PVN noradrenaline stimulates ATP release from glia which acts via P2X7 receptor mediated enhancement of cell surface AMPA receptor expression, to enhance glutamatergic tone (156). As such, astrocytes may mediate adrenaline/noradrenaline mediated positive feedback within the HPA-axis. In the context of the regulation of learning and memory, astrocytes have been implicated in mediating some of the effects of the noradrenaline system on this aspect of behaviour (157).

This article is protected by copyright. All rights reserved. 
In summary, stress impacts numerous aspects of physiology and behaviour. The potential role of glia in modulating the stress-associated changes in learning and memory have recently been reviewed elsewhere (158). While undoubtedly important players in mediating the response to stress, it remains to be fully clarified whether astrocytes form part of the negative feedback loop that regulates HPA-axis function by directly modulating activity of PVN CRH or AVP neurons. However, given the evidence of astrocytic involvement in regulation of PVN magnocellular AVP neuronal activity in the context of osmotic stress (128, 129) it seems highly likely.

\section{Astrocytes and the regulation of circadian rhythms}

To maximise survival most mammals time their peak activity to the presence (diurnal mammals) or absence (nocturnal mammals) of daylight, as appropriate. An internal master clock in the SCN receives information regarding light-dark cycles and uses this to entrain the rest of the body to a roughly 24-hour rhythm $(159,160)$. The 'hands' of the clock are formed through a molecular transcription-translation negative feedback loop (161). This loop involves many gene and protein interactions; the coordinated activity of CLOCK and brain and muscle aryl hydrocarbon receptor nuclear translocation factor-like protein 1 (BMAL1) to produce PERIOD (PER) and CRYPTOCHROME (CRY) proteins being essential. PER and CRY subsequently inhibit the transcriptional activity of CLOCK/BMAL1, which leads to degradation of PER and CRY, and so restarts the cycle. These clock genes are evolutionarily conserved throughout the animal kingdom, though different homologs exist across species. Found in most mammalian organs, these genes enable cell autonomous rhythmicity that may diverge from that of the SCN (160). Rhythmic expression of clock genes has been identified in astrocytes of the SCN, but how they contribute to circadian regulation is still being fully elucidated.

An abnormal light-dark cycle has a negative impact on health and can cause predisposition to health problems (162). Exposure to constant light or dark alters the expression of GFAP in the SCN, with an increased number of GFAP-immunoreactive cells observed in mice reared in constant light. Conversely, mice reared in constant dark conditions have a reduction in GFAP-immunoreactive cells in the SCN (163). Comparable observations have been made in

This article is protected by copyright. All rights reserved. 
rats and hamsters (164-166). This suggests that astrocytes are regulated by changes in the light-dark cycle.

In addition to being responsive to changes in the light-cycle, the activity of SCN neurons can impact astrocytes. Vasoactive intestinal peptide (VIP), one of the key SCN expressed neuropeptides, can entrain the rhythmic expression of Per2 in cultured astrocytes (167). Furthermore, GFAP-immunoreactive fibre coverage of VIP neurons are light dependent; with increased coverage during the dark phase/circadian night (168). Taken together, these data highlight the complexity of bidirectional control of astrocyte-neuron communication in the SCN.

Astrocytes are emerging as important controllers of the SCN circadian clock. Rhythmic expression of Bmal1 in astrocytes is important in regulating behaviour and cognition in mice. Inducible-deletion of Bmal1 from GLAST-positive astrocytes in mice results in altered locomotion, as well as reduced cognitive ability in a novel object recognition task (169). This appears to be mediated in part by alterations in SCN VIPimmunoreactivity and disruption of the rhythmic expression of Per2 and Bmal1 in the hippocampus and cortex, demonstrating the importance of astrocytes in regulating circadian rhythms. Of note, in the animals with inducible-deletion of Bmal1 in GLASTpositive cells, the percentage of non-astrocyte cells in the SCN expressing Bmal1immunoreactivity was also reduced. This suggests that loss of Bmal1 in GLAST-positive cells impacted cellular expression of this key circadian regulatory gene more widely (169). In vitro, knockdown of Bmal1 mRNA in astrocytes that are co-cultured with neurons is sufficient to impact the rhythmicity of the neuronal expression of clock genes (169). Furthermore, an independent study published contemporaneously demonstrated that knockdown Bmal1 expression specifically from SCN astrocytes in mice lengthens the circadian period, reflected through altered locomotor activity, and impacts SCN clock gene expression (170). Collectively, these studies suggest that astrocytic expression of Bmal1 is essential for normal circadian function.

This article is protected by copyright. All rights reserved. 
The molecular mechanisms by which astrocytes interact with neurons to impact circadian rhythms are beginning to be elucidated. $\mathrm{Ca}^{2+}$ imaging in cultured SCN slices from the mouse has identified anti-phasic circadian rhythms of $\mathrm{Ca}^{2+}$ oscillations between neurons and astrocytes, with astrocytes showing peak activity during the circadian night and neurons the circadian day (171). This is suggestive of a reciprocal activity relationship between the two cell types. Most neurons in the SCN are GABAergic (172), as such GABA as the key neurotransmitter regulating pacemaker activity in the SCN (173). In vitro, pharmacological inhibition of $\mathrm{GABA}_{A}$ receptors in neuron-astrocyte co-cultures is sufficient to prevent astrocyte-induced entrainment of key circadian genes in neurons, including Per2 (169), suggesting that GABAergic signalling is critical for astrocytic regulation of neuronal circadian function. This in vitro evidence is supported by the finding that mice with global inducible knock-out of Bmal1 in astrocytes display reduced SCN GABA transporter expression and increased cerebrospinal fluid concentrations of GABA, implicating dysregulation of GABA clearance from the extracellular space in the altered circadian phenotype of these animals (169). Indeed, administration of a $\mathrm{GABA}_{\mathrm{A}}$ receptor antagonist rescues the dysregulated circadian activity pattern and cognitive deficits in these animals.

Emerging research also supports astrocytic modulation of glutamatergic input as being critical in regulating SCN neurons. Extracellular glutamate levels in the SCN exhibit a circadian pattern, aligned to that of astrocytic $\mathrm{Ca}^{2+}$ signalling (171). The activity of glutamine synthetase (GS) is also circadian-dependent (174) and glutamate uptake is considerably hindered in astrocytes cultured from Clock and Per2 deficient mice (175), further supporting a key role for glutamatergic signalling in the regulation of the SCN clock. Brancaccio and colleagues have developed a model for how astrocytic release of glutamate during the circadian night enhances GABAergic tone in SCN neurons; thus, contributing to inhibition of the circuit during that time period and explaining the anti-phasic circadian activity of SCN astrocytes and neurons (171).

In vivo evidence supports a key role for astrocytes in control of SCN periodicity. Floxed CK1 $\varepsilon^{\text {tau/tau }}$ mice display a $20 \mathrm{~h}$ wheel-running activity pattern rhythm in constant darkness. CRE-mediated deletion of $\mathrm{CK} 1 \varepsilon^{\text {tau/tau }}$ specifically from SCN astrocytes is sufficient to restore the behavioural activity in these mice to a 24-hour pattern (171); thus, indicating that astrocytes can impact the intrinsic

This article is protected by copyright. All rights reserved. 
activity of the SCN master clock. Indeed, even in the absence of a viable circadian clock (Cry1/2-null mice) reintroduction of Cry1 to SCN GFAP-expressing astrocytes is enough to enable mice to develop an intrinsic rhythmical pattern of behaviour even when maintained in constant darkness (176). This is mediated, at least in part, via astrocyte-driven glutamatergic regulation of SCN neuronal activity (176). These seminal studies indicate that SCN astrocyte-communication plays a prominent role in maintaining circadian function. A schematic summary of the current understanding of how astrocytes may impact the control of circadian rhythms by the SCN can be found in Figure 6 .

\section{Summary and conclusions}

Astrocytes play a fundamental role in monitoring and responding to changes in hormones and nutrients as they penetrate the brain or are released locally. The structural apposition of astrocytes to both cerebral blood vessels (together with pericytes) and neurons allows coupling of these cues to changes in the activity of astrocytes and subsequently neurons. Over the past decade or so, the generation of astrocyte-specific genetic manipulations in mice has permitted the assessment of glial roles in regulating whole body physiology, including (but not limited to) regulation of food intake, glucose homeostasis, reproduction, fluid balance, breathing and blood pressure regulation. Emerging technological advancements permitting more spatially and temporally-targeted manipulation of astrocytes will enable previously unknown astrocyte functions to be described. Going forward, better classification of astrocytes into specific subtypes, akin to those of neurons (i.e. glutamatergic and GABAergic neurons) is fundamentally required and will allow yet more detailed examination of the astrocyte contribution to neuroendocrine function. This will clearly be challenging given that astrocytes are highly plastic cells, reacting and adapting to new physiological and pathophysiological environments. Importantly, assessment of astrocyte function and the gliotransmitters they release (and their receptors) may expose potential therapeutic targets for treatment of significant public health challenges including obesity, diabetes and endocrine disorders such as hypothyroidism and hypogonadism.

This article is protected by copyright. All rights reserved. 


\section{Acknowledgements}

The authors declare no conflicts of interest. This work was supported by grants from the Medical Research Council (MR/N012763/1 KLJE and CB), Diabetes UK (RD Lawrence Fellowship to $C B ; 13 / 0004647)$ and internal funding from the University of Exeter Medical School (which supports NAM and JLR). AJM receives support from the Medical Research Council GW4 Biomed Doctoral Training Programme (MR/N0137941/1).

\section{Figure Legends}

Figure 1: Schematic overview of the proposed mechanisms by which astrocytes can impact neuroendocrine systems. (1) As a key component of the blood-brain barrier (BBB), astrocytes may impact entry of circulating factors, including hormones and nutrients in to the CNS. (2) Like neurons, astrocytes are direct targets of hormone action in the CNS via receptors expressed on their surface. (3) Astrocytes are a source of bioactive signalling molecules including gliotransmitters, and neurosteroids. Astrocytes also regulate neurotransmitter availability in the synaptic cleft through reuptake and recycling of neurotransmitters. (4) Morphological changes in astrocytes results in ensheathment of synapses which impacts synapse stability and extra-synaptic communication.

Figure 2: Simplified schematic summary of mechanisms by which hypothalamic astrocytes regulate neuroendocrine control of feeding. (1) Astrocytes of the hypothalamus express receptors for key homeostatic hormones, including leptin and ghrelin; (2) Deletion of leptin receptors and changes in diet alter the synaptic ensheathment of neighbouring neurons which control feeding; (3) Chronic leptin or ghrelin administration, and changes in food intake, change the expression of glial glutamate and glucose transporters in the medial basal hypothalamus; (4) Hypothalamic astrocytes show inflammatory responses and morphological plasticity in response to intake of a high-fat diet and manipulation of these inflammatory pathways (namely the NF-kb pathway) in astrocytes modulates feeding and can be protective against diet-induced obesity.

This article is protected by copyright. All rights reserved. 
Figure 3: Simplified schematic summary of mechanisms by which astrocytes regulate glucose homeostasis. (1) Astrocytes express glucose transporter (GLUT) 1 and 2 and their expression is involved in stimulating the counterregulatory response (CRR) to hypoglycaemia; (2) Reduced expression of glial glutamate transporters after recurrent hypoglycaemia disrupts glutamatergic neurotransmission necessary for the appropriate CRR; (3) Astrocytes store glycogen and use this to provide fuel to neurons during glucose deprivation, however glycogen supercompenstation following recurrent hypoglycaemia may blunt the CRR; (4) Inflammation and astrogliosis are observed in mouse models of diabetes and modulation of astrocyte NF-KB signalling is protective against diet-induced glucose intolerance; (5) By releasing gliotransmitters, altering physical contact, and reuptake of neurotransmitters, astrocytes modulate neurons in the brainstem and hypothalamus to control neuronal responses to changes in glucose availability.

Figure 4: Simplified schematic summary of mechanisms by which hypothalamic astrocytes regulate neuroendocrine control of reproduction. (1) Astrocytes of the hypothalamus express receptors for numerous neuropeptides and hormones including oestradiol, vasoactive intestinal polypeptide (VIP), neuregulin, and oxytocin; (2) Stimulation of certain receptors on astrocytes (namely epidermal growth factor B4 [erbB4], oxytocin, and insulin receptors) leads to release of prostaglandin E2 (PGE2) which acts on prostaglandin E2 receptor 2 (EP2R) on GnRH neurons to increase firing and GnRH secretion; (3) Astrocytes are responsible for the reuptake and synthesis of glutamate and the levels of proteins required for this process vary throughout reproductive maturation; (4) Gap junction connections between astrocytes and GnRH neurons may allow for synchronous firing and hormone release between spatially separated neurons. The net effect of these mechanisms is to modulate $\mathrm{GnRH}$ secretion, a master regulator of reproductive function.

Figure 5: Simplified schematic summary of mechanisms by which astrocytes modulate the neuroendocrine regulation of fluid homeostasis. (1) Astrocytes in the hypothalamus express receptors for arginine vasopressin (AVP; V3R, V1aR, and V1bR) and angiotensin II (Angll; $\mathrm{AT}_{1} \mathrm{R}$ ). During hyperosmotic events, $\mathrm{AVP}$ and Angll activate intracellular signalling pathways in astrocytes which increase intracellular $\mathrm{Ca}^{2+} ;(2)$ Increases in intracellular $\mathrm{Ca}^{2+}$ lead to increased glutamate release from astrocyte which may act on neurons to drive phasic firing and AVP release; (3) Taurine is released from astrocytes under hypo-osmotic

This article is protected by copyright. All rights reserved. 
stress which can inhibit AVP neurons by activating neuronal glycine receptors; (4) Astrocytes of the supraoptic nucleus show morphological changes and c-FOS expression in response to dehydration and in vitro astrocytes swell in response to hypo-osmotic stress. Thus, astrocytes can sense and respond to changes in fluid homeostasis.

Figure 6: Simplified schematic summary of mechanisms by which hypothalamic astrocytes regulate the circadian 'master' clock of the suprachiasmatic nucleus. The suprachiasmatic nucleus ( $\mathrm{SCN}$ ) within the hypothalamus is responsible for entraining daily rhythms to the light-dark cycle. (A) Within the SCN, astrocytes have rhythmic oscillations in $\mathrm{Ca}^{2+}$ anti-phasic with those seen in neurons: astrocytes showing peak activity during the circadian night and neurons the circadian day. (B) Within SCN the bi-directional communication between neurons and astrocytes is important for maintaining integrity of the master circadian clock: (1) Astrocytic recycling of glutamate and GABA contributes to regulation of SCN neuron activity; (2) Vasoactive intestinal peptide (VIP), a key neuropeptide transmitter in the SCN, can entrain rhymical expression of 'circadian clock genes' in astrocytes; (3) Astrocyte ensheathment of SCN VIP neurons is light dependent, with increased coverage during the circadian night.

\section{References}

1. Ebling FJP, Lewis JE. Tanycytes and hypothalamic control of energy metabolism. Glia. 2018; 66(6): 1176-84.

2. Lewis JE, Ebling FJ. Tanycytes As Regulators of Seasonal Cycles in Neuroendocrine Function. Front Neurol. 2017; 879.

3. Rosso L, Mienville JM. Pituicyte modulation of neurohormone output. Glia. 2009; 57(3): 23543.

4. Verkhratsky A, Nedergaard M. Physiology of Astroglia. Physiol Rev. 2018; 98(1): 239-389.

5. Banker GA. Trophic interactions between astroglial cells and hippocampal neurons in culture. Science. 1980; 209(4458): 809-10.

6. Allen NJ, Bennett ML, Foo LC, Wang GX, Chakraborty C, Smith SJ, Barres BA. Astrocyte glypicans 4 and 6 promote formation of excitatory synapses via GluA1 AMPA receptors. Nature. 2012; 486(7403): 410-4.

7. Christopherson KS, Ullian EM, Stokes CC, Mullowney CE, Hell JW, Agah A, Lawler J, Mosher DF, Bornstein P, Barres BA. Thrombospondins are astrocyte-secreted proteins that promote CNS synaptogenesis. Cell. 2005; 120(3): 421-33.

8. Chung WS, Clarke LE, Wang GX, Stafford BK, Sher A, Chakraborty C, Joung J, Foo LC, Thompson A, Chen C, Smith SJ, Barres BA. Astrocytes mediate synapse elimination through MEGF10 and MERTK pathways. Nature. 2013; 504(7480): 394-400.

This article is protected by copyright. All rights reserved. 
9. Kucukdereli $\mathrm{H}$, Allen NJ, Lee AT, Feng A, Ozlu MI, Conatser LM, Chakraborty C, Workman G, Weaver M, Sage EH, Barres BA, Eroglu C. Control of excitatory CNS synaptogenesis by astrocytesecreted proteins Hevin and SPARC. Proc Natl Acad Sci U S A. 2011; 108(32): E440-9.

10. Farmer WT, Murai K. Resolving Astrocyte Heterogeneity in the CNS. Front Cell Neurosci. 2017; 11300.

11. Xin W, Bonci A. Functional Astrocyte Heterogeneity and Implications for Their Role in Shaping Neurotransmission. Front Cell Neurosci. 2018; 12141.

12. Molofsky AV, Deneen B. Astrocyte development: A Guide for the Perplexed. Glia. 2015; 63(8): 1320-9.

13. Boisvert MM, Erikson GA, Shokhirev MN, Allen NJ. The Aging Astrocyte Transcriptome from Multiple Regions of the Mouse Brain. Cell Rep. 2018; 22(1): 269-85.

14. Burda JE, Sofroniew MV. Reactive gliosis and the multicellular response to CNS damage and disease. Neuron. 2014; 81(2): 229-48.

15. Sofroniew MV. Astrocyte barriers to neurotoxic inflammation. Nat Rev Neurosci. 2015; 16(5): 249-63.

16. Morizawa YM, Hirayama Y, Ohno N, Shibata S, Shigetomi E, Sui Y, Nabekura J, Sato K, Okajima F, Takebayashi H, Okano H, Koizumi S. Reactive astrocytes function as phagocytes after brain ischemia via ABCA1-mediated pathway. Nat Commun. 2017; 8(1): 28.

17. Clarke LE, Liddelow SA, Chakraborty C, Munch AE, Heiman M, Barres BA. Normal aging induces A1-like astrocyte reactivity. Proc Natl Acad Sci U S A. 2018; 115(8): E1896-E905.

18. Liddelow SA, Guttenplan KA, Clarke LE, Bennett FC, Bohlen CJ, Schirmer L, Bennett ML, Munch AE, Chung WS, Peterson TC, Wilton DK, Frouin A, Napier BA, Panicker N, Kumar $M$, Buckwalter MS, Rowitch DH, Dawson VL, Dawson TM, Stevens B, Barres BA. Neurotoxic reactive astrocytes are induced by activated microglia. Nature. 2017; 541(7638): 481-7.

19. Zamanian JL, Xu L, Foo LC, Nouri N, Zhou L, Giffard RG, Barres BA. Genomic analysis of reactive astrogliosis. J Neurosci. 2012; 32(18): 6391-410.

20. Murray PJ, Allen JE, Biswas SK, Fisher EA, Gilroy DW, Goerdt S, Gordon S, Hamilton JA, Ivashkiv LB, Lawrence T, Locati M, Mantovani A, Martinez FO, Mege JL, Mosser DM, Natoli G, Saeij JP, Schultze JL, Shirey KA, Sica A, Suttles J, Udalova I, van Ginderachter JA, Vogel SN, Wynn TA. Macrophage activation and polarization: nomenclature and experimental guidelines. Immunity. 2014; 41(1): 14-20.

21. Basco E, Woodhams PL, Hajos F, Balazs R. Immunocytochemical demonstration of glial fibrillary acidic protein in mouse tanycytes. Anat Embryol (Berl). 1981; 162(2): 217-22.

22. Cahoy JD, Emery B, Kaushal A, Foo LC, Zamanian JL, Christopherson KS, Xing Y, Lubischer JL, Krieg PA, Krupenko SA, Thompson WJ, Barres BA. A transcriptome database for astrocytes, neurons, and oligodendrocytes: a new resource for understanding brain development and function. I Neurosci. 2008; 28(1): 264-78.

23. Abbott NJ, Ronnback L, Hansson E. Astrocyte-endothelial interactions at the blood-brain barrier. Nat Rev Neurosci. 2006; 7(1): 41-53.

24. De Souza CT, Araujo EP, Bordin S, Ashimine R, Zollner RL, Boschero AC, Saad MJA, Velloso LA. Consumption of a fat-rich diet activates a proinflammatory response and induces insulin resistance in the hypothalamus. Endocrinology. 2005; 146(10): 4192-9.

25. Zhang X, Zhang G, Zhang H, Karin M, Bai H, Cai D. Hypothalamic IKK $\beta / N F-K B$ and ER Stress Link Overnutrition to Energy Imbalance and Obesity. Cell. 2008; 135(1): 61-73.

26. Horvath TL, Sarman B, García-Cáceres C, Enriori PJ, Sotonyi P, Shanabrough M, Borok E, Argente J, Chowen JA, Perez-Tilve D, Pfluger PT, Brönneke HS, Levin BE, Diano S, Cowley Ma, Tschöp $\mathrm{MH}$. Synaptic input organization of the melanocortin system predicts diet-induced hypothalamic reactive gliosis and obesity. Proceedings of the National Academy of Sciences of the United States of America. 2010; 107(33): 14875-80.

27. Buckman LB, Thompson MM, Moreno HN, Ellacott KLJ. Regional astrogliosis in the mouse hypothalamus in response to obesity. Journal of Comparative Neurology. 2013; 521(6): 1322-33.

This article is protected by copyright. All rights reserved. 
28. Thaler J, Yi C, Schur E, Guyenet S, Hwang B, Dietrich M, Zhao X, Sarruf D, Izgur V, Maravilla K, Nguyen H, Fischer J, Matsen M, Wisse B, Morton G, Horvarth T, Baskin D, Tshop M, Schwartz M. Obesity is associated with hypothalamic injury in rodents and humans. Journal of Clinical Investigation. 2012; 122(1): 153-.

29. Berkseth KE, Guyenet SJ, Melhorn SJ, Lee D, Thaler JP, Schur EA, Schwartz MW. Hypothalamic gliosis associated with high-fat diet feeding is reversible in mice: A combined immunohistochemical and magnetic resonance imaging study. Endocrinology. 2014; 155(8): 285867.

30. Zhang Y, Reichel JM, Han C, Zuniga-Hertz JP, Cai D. Astrocytic Process Plasticity and IKK $\beta /$ NFKB in Central Control of Blood Glucose, Blood Pressure, and Body Weight. Cell Metabolism. 2017; 25(5): 1091-102.e4.

31. Douglass JD, Dorfman MD, Fasnacht R, Shaffer LD, Thaler JP. Astrocyte IKK $\beta / N F-K B$ signaling is required for diet-induced obesity and hypothalamic inflammation. Molecular Metabolism. 2017; 0(0): 366-73.

32. Balland E, Cowley MA. Short-term high fat diet increases the presence of astrocytes in the hypothalamus of C57BL6 mice without altering leptin sensitivity. Journal of Neuroendocrinology. 20170-3.

33. Buckman LB, Thompson MM, Lippert RN, Blackwell TS, Yull FE, Ellacott KLJ. Evidence for a novel functional role of astrocytes in the acute homeostatic response to high-fat diet intake in mice. Molecular Metabolism. 2015; 4(1): 58-63.

34. Chen N, Sugihara H, Kim J, Fu Z, Barak B, Sur M, Feng G, Han W. Direct modulation of GFAPexpressing glia in the arcuate nucleus bi-directionally regulates feeding. eLife. 2016; 51-21.

35. Fuente-Martín E, García-Cáceres C, Argente-Arizón P, Díaz F, Granado M, Freire-Regatillo A, Castro-González D, Ceballos ML, Frago LM, Dickson SL, Argente J, Chowen JA. Leptin Regulates Glucose and Glutamate Transporters in Hypothalamic Astrocytes. Journal of Clinical Investigation. 2012; 122(11): 3900-13.

36. Cheunsuang $\mathrm{O}$, Morris R. Astrocytes in the arcuate nucleus and median eminence that take up a fluorescent dye from the circulation express leptin receptors and neuropeptide $Y$ Y1 receptors. Glia. 2005; 52(3): 228-33.

37. Hsuchou H, He Y, Kastin AJ, Tu H, Markadakis EN, Rogers RC, Fossier PB, Pan W. Obesity induces functional astrocytic leptin receptors in hypothalamus. Brain. 2009; 132(4): 889-902.

38. Pan W, Hsuchou H, He Y, Sakharkar A, Cain C, Yu C, Kastin AJ. Astrocyte leptin receptor (ObR) and leptin transport in adult-onset obese mice. Endocrinology. 2008; 149(6): 2798-806.

39. García-Cáceres C, Fuente-Martán E, Burgos-Ramos E, Granado M, Frago LM, Barrios V, Horvath T, Argente J, Chowen JA. Differential acute and chronic effects of leptin on hypothalamic astrocyte morphology and synaptic protein levels. Endocrinology. 2011; 152(5): 1809-18.

40. Kim JG, Suyama S, Koch M, Jin S, Argente-Arizon P, Argente J, Liu Z-W, Zimmer MR, Jeong JK, Szigeti-Buck K, Gao Y, Garcia-Caceres C, Yi C-X, Salmaso N, Vaccarino FM, Chowen J, Diano S, Dietrich $\mathrm{MO}$, Tschöp MH, Horvath TL. Leptin signaling in astrocytes regulates hypothalamic neuronal circuits and feeding. Nature Neuroscience. 2014; 17(7): 908-10.

41. Wang Y, Hsuchou H, He Y, Kastin AJ, Pan W. Role of Astrocytes in Leptin Signaling. Journal of Molecular Neuroscience. 2015; 56(4): 829-39.

42. Rottkamp DM, Rudenko IA, Maier MT, Roshanbin S, Yulyaningsih E, Perez L, Valdearcos M, Chua S, Koliwad SK, Xu AW. Leptin potentiates astrogenesis in the developing hypothalamus. Molecular Metabolism. 2015; 4(11): 881-9.

43. Fuente-Martín E, García-Cáceres C, Argente-Arizón P, Díaz F, Granado M, Freire-Regatillo A, Castro-González D, Ceballos ML, Frago LM, Dickson SL, Argente J, Chowen JA. Ghrelin Regulates Glucose and Glutamate Transporters in Hypothalamic Astrocytes. Scientific reports. 2016; 6(November 2015): 23673-.

44. Baquedano E, Chowen JA, Argente J, Frago LM. Differential effects of GH and GH-releasing peptide-6 on astrocytes. Journal of Endocrinology. 2013; 218(3): 263-74.

This article is protected by copyright. All rights reserved. 
45. García-Cáceres C, Fuente-Martín E, Díaz F, Granado M, Argente-Arizón P, Frago LM, FreireRegatillo A, Barrios V, Argente J, Chowen JA. The opposing effects of ghrelin on hypothalamic and systemic inflammatory processes are modulated by its acylation status and food intake in male rats. Endocrinology. 2014; 155(8): 2868-80.

46. Yang L, Qi Y, Yang Y. Astrocytes Control Food Intake by Inhibiting AGRP Neuron Activity via Adenosine A<inf>1</inf> Receptors. Cell Reports. 2015; 11(5): 798-807.

47. Sweeney $P, Q i$ Y, Xu Z, Yang Y. Activation of hypothalamic astrocytes suppresses feeding without altering emotional states. Glia. 20161-11.

48. Scofield MD, Boger HA, Smith RJ, Li H, Haydon PG, Kalivas PW. Gq-DREADD selectively initiates glial glutamate release and inhibits cue-induced cocaine seeking. Biological Psychiatry. 2015; 78(7): 441-51.

49. Scofield MD, Li H, Siemsen BM, Healey KL, Tran PK, Woronoff N, Boger HA, Kalivas PW, Reissner KJ. Cocaine Self-Administration and Extinction Leads to Reduced Glial Fibrillary Acidic Protein Expression and Morphometric Features of Astrocytes in the Nucleus Accumbens Core. Biological Psychiatry. 2016; 80(3): 207-15.

50. Rossi MA, Stuber GD. Overlapping Brain Circuits for Homeostatic and Hedonic Feeding. Cell Metabolism. 2017(2017).

51. Reiner DJ, Mietlicki-Baase EG, McGrath LE, Zimmer DJ, Bence KK, Sousa GL, Konanur VR, Krawczyk J, Burk DH, Kanoski SE, Hermann GE, Rogers RC, Hayes MR. Astrocytes Regulate GLP-1 Receptor-Mediated Effects on Energy Balance. Journal of Neuroscience. 2016; 36(12): 3531-40.

52. Cork SC, Richards JE, Holt MK, Gribble FM, Reimann F, Trapp S. Distribution and characterisation of Glucagon-like peptide-1 receptor expressing cells in the mouse brain. Molecular Metabolism. 2015; 4(10): 718-31.

53. Bartolome JV, Bartolome MB, Harris EB, Pauk JS, Schanberg SM. Regulation of insulin and glucose plasma levels by central nervous system beta-endorphin in preweanling rats. Endocrinology. 1989; 124(5): 2153-8.

54. Konner AC, Janoschek R, Plum L, Jordan SD, Rother E, Ma X, Xu C, Enriori P, Hampel B, Barsh GS, Kahn CR, Cowley MA, Ashcroft FM, Bruning JC. Insulin action in AgRP-expressing neurons is required for suppression of hepatic glucose production. Cell Metab. 2007; 5(6): 438-49.

55. Tong $Q$, Ye C, McCrimmon RJ, Dhillon H, Choi B, Kramer MD, Yu J, Yang Z, Christiansen LM, Lee CE, Choi CS, Zigman JM, Shulman GI, Sherwin RS, Elmquist JK, Lowell BB. Synaptic glutamate release by ventromedial hypothalamic neurons is part of the neurocircuitry that prevents hypoglycemia. Cell Metab. 2007; 5(5): 383-93.

56. McDougal DH, Hermann GE, Rogers RC. Astrocytes in the nucleus of the solitary tract are activated by low glucose or glucoprivation: evidence for glial involvement in glucose homeostasis. Frontiers in Neuroscience. 2013; 7.

57. Chowdhury GMI, Wang P, Ciardi A, Mamillapalli R, Johnson J, Zhu W, Eid T, Behar K, Chan O. Impaired Glutamatergic Neurotransmission in the Ventromedial Hypothalamus May Contribute to Defective Counterregulation in Recurrently Hypoglycemic Rats. Diabetes. 2017; 66(7): 1979-89.

58. Marty N, Dallaporta M, Foretz M, Emery M, Tarussio D, Bady I, Binnert C, Beermann F, Thorens B. Regulation of glucagon secretion by glucose transporter type 2 (glut2) and astrocytedependent glucose sensors. J Clin Invest. 2005; 115(12): 3545-53.

59. García-Cáceres C, Quarta C, Varela L, Gao Y, Gruber T, Legutko B, Jastroch M, Johansson P, Ninkovic J, Yi CX, Le Thuc O, Szigeti-Buck K, Cai W, Meyer CW, Pfluger PT, Fernandez AM, Luquet S, Woods SC, Torres-Alemán I, Kahn CR, Götz M, Horvath TL, Tschöp MH. Astrocytic Insulin Signaling Couples Brain Glucose Uptake with Nutrient Availability. Cell. 2016; 166(4): 867-80.

60. Chari M, Yang CS, Lam CK, Lee K, Mighiu P, Kokorovic A, Cheung GW, Lai TY, Wang PY, Lam TK. Glucose transporter-1 in the hypothalamic glial cells mediates glucose sensing to regulate glucose production in vivo. Diabetes. 2011; 60(7): 1901-6.

This article is protected by copyright. All rights reserved. 
61. Cataldo AM, Broadwell RD. Cytochemical identification of cerebral glycogen and glucose-6phosphatase activity under normal and experimental conditions. II. Choroid plexus and ependymal epithelia, endothelia and pericytes. J Neurocytol. 1986; 15(4): 511-24.

62. Brown AM, Sickmann HM, Fosgerau K, Lund TM, Schousboe A, Waagepetersen HS, Ransom BR. Astrocyte glycogen metabolism is required for neural activity during aglycemia or intense stimulation in mouse white matter. J Neurosci Res. 2005; 79(1-2): 74-80.

63. Alquier T, Kawashima J, Tsuji Y, Kahn BB. Role of hypothalamic adenosine 5'monophosphate-activated protein kinase in the impaired counterregulatory response induced by repetitive neuroglucopenia. Endocrinology. 2007; 148(3): 1367-75.

64. Herzog RI, Chan O, Yu S, Dziura J, McNay EC, Sherwin RS. Effect of acute and recurrent hypoglycemia on changes in brain glycogen concentration. Endocrinology. 2008; 149(4): 1499-504.

65. Duarte JMN, Morgenthaler FD, Gruetter R. Glycogen Supercompensation in the Rat Brain After Acute Hypoglycemia is Independent of Glucose Levels During Recovery. Neurochem Res. 2017; 42(6): 1629-35.

66. Oz G, DiNuzzo M, Kumar A, Moheet A, Khowaja A, Kubisiak K, Eberly LE, Seaquist ER. Cerebral glycogen in humans following acute and recurrent hypoglycemia: Implications on a role in hypoglycemia unawareness. J Cereb Blood Flow Metab. 2017; 37(8): 2883-93.

67. Saravia FE, Revsin Y, Gonzalez Deniselle MC, Gonzalez SL, Roig P, Lima A, Homo-Delarche F, De Nicola AF. Increased astrocyte reactivity in the hippocampus of murine models of type 1 diabetes: the nonobese diabetic (NOD) and streptozotocin-treated mice. Brain Res. 2002; 957(2): 345-53.

68. Afsari ZH, Renno WM, Abd-El-Basset E. Alteration of glial fibrillary acidic proteins immunoreactivity in astrocytes of the spinal cord diabetic rats. Anat Rec (Hoboken). 2008; 291(4): 390-9.

69. Garcia-Caceres C, Lechuga-Sancho A, Argente J, Frago LM, Chowen JA. Death of hypothalamic astrocytes in poorly controlled diabetic rats is associated with nuclear translocation of apoptosis inducing factor. J Neuroendocrinol. 2008; 20(12): 1348-60.

70. Fernandez-Agullo T. Thyrotropin-releasing hormone and its receptor in glia. Glia. 2001; 33(4): 267-76.

71. Hartel K, Schnell C, Hulsmann S. Astrocytic calcium signals induced by neuromodulators via functional metabotropic receptors in the ventral respiratory group of neonatal mice. Glia. 2009; 57(8): 815-27.

72. McDermott AM, Dickinson SL, Wilkin GP. Thyrotropin releasing hormone (TRH) and a degradation stabilized analogue (RX77368) stimulate phosphoinositide turnover in cultured astrocytes in a regionally specific manner. Neurochem Int. 1992; 20(3): 307-13.

73. Braun D, Kinne A, Brauer AU, Sapin R, Klein MO, Kohrle J, Wirth EK, Schweizer U. Developmental and cell type-specific expression of thyroid hormone transporters in the mouse brain and in primary brain cells. Glia. 2011; 59(3): 463-71.

74. Wirth EK, Schweizer U, Kohrle J. Transport of thyroid hormone in brain. Front Endocrinol (Lausanne). 2014; 598.

75. Guadano-Ferraz A, Obregon MJ, St Germain DL, Bernal J. The type 2 iodothyronine deiodinase is expressed primarily in glial cells in the neonatal rat brain. Proc Natl Acad Sci U S A. 1997; 94(19): 10391-6.

76. Tu HM, Kim SW, Salvatore D, Bartha T, Legradi G, Larsen PR, Lechan RM. Regional distribution of type 2 thyroxine deiodinase messenger ribonucleic acid in rat hypothalamus and pituitary and its regulation by thyroid hormone. Endocrinology. 1997; 138(8): 3359-68.

77. Gereben B, Zavacki AM, Ribich S, Kim BW, Huang SA, Simonides WS, Zeold A, Bianco AC. Cellular and molecular basis of deiodinase-regulated thyroid hormone signaling. Endocr Rev. 2008; 29(7): 898-938.

This article is protected by copyright. All rights reserved. 
78. Werneck de Castro JP, Fonseca TL, Ueta CB, McAninch EA, Abdalla S, Wittmann G, Lechan RM, Gereben B, Bianco AC. Differences in hypothalamic type 2 deiodinase ubiquitination explain localized sensitivity to thyroxine. J Clin Invest. 2015; 125(2): 769-81.

79. Fonseca TL, Correa-Medina M, Campos MP, Wittmann G, Werneck-de-Castro JP, Arrojo e Drigo R, Mora-Garzon M, Ueta CB, Caicedo A, Fekete C, Gereben B, Lechan RM, Bianco AC. Coordination of hypothalamic and pituitary T3 production regulates TSH expression. $J$ Clin Invest. 2013; 123(4): 1492-500.

80. Fonseca TL, Werneck-De-Castro JP, Castillo M, Bocco BM, Fernandes GW, McAninch EA, Ignacio DL, Moises CC, Ferreira AR, Gereben B, Bianco AC. Tissue-specific inactivation of type 2 deiodinase reveals multilevel control of fatty acid oxidation by thyroid hormone in the mouse. Diabetes. 2014; 63(5): 1594-604.

81. Sayre NL, Sifuentes M, Holstein D, Cheng SY, Zhu X, Lechleiter JD. Stimulation of astrocyte fatty acid oxidation by thyroid hormone is protective against ischemic stroke-induced damage. $J$ Cereb Blood Flow Metab. 2017; 37(2): 514-27.

82. Igelhorst BA, Niederkinkhaus V, Karus C, Lange MD, Dietzel ID. Regulation of neuronal excitability by release of proteins from glial cells. Philos Trans $R$ Soc Lond B Biol Sci. 2015; 370(1672).

83. Mendes-de-Aguiar CB, Alchini R, Decker $\mathrm{H}$, Alvarez-Silva $\mathrm{M}$, Tasca $\mathrm{Cl}$, Trentin AG. Thyroid hormone increases astrocytic glutamate uptake and protects astrocytes and neurons against glutamate toxicity. J Neurosci Res. 2008; 86(14): 3117-25.

84. Mohacsik P, Zeold A, Bianco AC, Gereben B. Thyroid hormone and the neuroglia: both source and target. J Thyroid Res. 2011; 2011215718.

85. Constantin S, Caraty A, Wray S, Duittoz AH. Development of gonadotropin-releasing hormone-1 secretion in mouse nasal explants. Endocrinology. 2009; 150(7): 3221-7.

86. Tsukahara S, Maekawa F, Tsukamura H, Hirunagi K, Maeda K. Morphological characterization of relationship between gap junctions and gonadotropin releasing hormone nerve terminals in the rat median eminence. Neuroscience letters. 1999; 261(1-2): 105-8.

87. Gulinello M, Etgen AM. Sexually dimorphic hormonal regulation of the gap junction protein, CX43, in rats and altered female reproductive function in CX43+/- mice. Brain Research. 2005; 1045(1-2): 107-15.

88. Pinet-Charvet C, Geller S, Desroziers E, Ottogalli M, Lomet D, Georgelin C, Tillet $Y$, Franceschini I, Vaudin P, Duittoz A. GnRH episodic secretion is altered by pharmacological blockade of gap junctions: Possible involvement of glial cells. Endocrinology. 2016; 157(1): 304-22.

89. Kumar S, Parkash J, Kataria H, Kaur G. Enzymatic removal of polysialic acid from neural cell adhesion molecule interrupts gonadotropin releasing hormone (GnRH) neuron-glial remodeling. Molecular and Cellular Endocrinology. 2012; 348(1): 95-103.

90. Parent AS, Mungenast AE, Lomniczi A, Sandau US, Peles E, Bosch MA, Rønnekleiv OK, Ojeda SR. A contactin-receptor-like protein tyrosine phosphatase $\beta$ complex mediates adhesive communication between astroglial cells and gonadotrophin-releasing hormone neurones. Journal of Neuroendocrinology. 2007; 19(11): 847-58.

91. Sandau US, Mungenast AE, Alderman Z, Sardi SP, Fogel Al, Taylor B, Parent AS, Biederer T, Corfas G, Ojeda SR. SynCAM1, a synaptic adhesion molecule, is expressed in astrocytes and contributes to erbB4 receptor-mediated control of female sexual development. Endocrinology. 2011; 152(6): 2364-76.

92. Sandau US, Mungenast AE, McCarthy J, Biederer T, Corfas G, Ojeda SR. The synaptic cell adhesion molecule, SynCAM1, mediates astrocyte-to- astrocyte and astrocyte-to-GnRH neuron adhesiveness in the mouse hypothalamus. Endocrinology. 2011; 152(6): 2353-63.

93. Baroncini M, Allet C, Leroy D, Beauvillain JC, Francke JP, Prevot V. Morphological evidence for direct interaction between gonadotrophin-releasing hormone neurones and astroglial cells in the human hypothalamus. Journal of Neuroendocrinology. 2007; 19(9): 691-702.

This article is protected by copyright. All rights reserved. 
94. Kuo J, Hamid N, Bondar G, Prossnitz ER, Micevych P. Membrane estrogen receptors stimulate intracellular calcium release and progesterone sysnthesis in hypothalamic astrocytes. Journal of Neuroscience. 2010; 30(39): 12950-7.

95. Cashion AB, Smith MJ, Wise PM. The morphometry of astrocytes in the rostral preoptic area exhibits a diurnal rhythm on proestrus: Relationship to the luteinizing hormone surge and effects of age. Endocrinology. 2003; 144(1): 274-80.

96. Gerhold LM, Wise PM. Vasoactive intestinal polypeptide regulates dynamic changes in astrocyte morphometry: Impact on gonadotropin-releasing hormone neurons. Endocrinology. 2006; 147(5): 2197-202.

97. Rage F, Lee BJ, Ma YJ, Ojeda SR. Estradiol enhances prostaglandin E2 receptor gene expression in luteinizing hormone-releasing hormone (LHRH) neurons and facilitates the LHRH response to PGE2 by activating a glia-to-neuron signaling pathway. The Journal of neuroscience : the official journal of the Society for Neuroscience. 1997; 17(23): 9145-56.

98. Clasadonte J, Poulain P, Hanchate NK, Corfas G, Ojeda SR, Prevot V. Prostaglandin E2 release from astrocytes triggers gonadotropin-releasing hormone $(\mathrm{GnRH})$ neuron firing via EP2 receptor activation. Proceedings of the National Academy of Sciences. 2011; 108(38): 16104-9.

99. Prevot V, Rio C, Cho GJ, Lomniczi A, Heger S, Neville CM, Rosenthal Na, Ojeda SR, Corfas G. Normal Female Sexual Development Requires Neuregulin - erbB Receptor Signaling in Hypothalamic Astrocytes. The Journal of Neuroscience. 2003; 23(1): 230-9.

100. Li B, Yang Z, Hou J, McCracken A, Jennings MA, Ma MYJ. Compromised reproductive function in adult female mice selectively expressing mutant ErbB-1 tyrosine kinase receptors in astroglia. Molecular endocrinology (Baltimore, Md). 2003; 17(11): 2365-76.

101. Parent AS, Rasier G, Matagne V, Lomniczi A, Lebrethon MC, Gérard A, Ojeda SR, Bourguignon JP. Oxytocin facilitates female sexual maturation through a glia-to-neuron signaling pathway. Endocrinology. 2008; 149(3): 1358-65.

102. Manaserh IH, Chikkamenahalli L, Ravi S, Dube PR, Park JJ, Hill JW. Ablating astrocyte insulin receptors leads to delayed puberty and hypogonadism in mice. PLoS Biol. 2019; 17(3): e3000189.

103. Glanowska KM, Moenter SM. Endocannabinoids and prostaglandins both contribute to GnRH neuron-GABAergic afferent local feedback circuits. Journal of Neurophysiology. 2011; 106(6): 3073-81.

104. Roth CL, McCormack AL, Lomniczi A, Mungenast AE, Ojeda SR. Quantitative proteomics identifies a change in glial glutamate metabolism at the time of female puberty. Molecular and Cellular Endocrinology. 2006; 254-25551-9.

105. Hatton Gl, Tweedle CD. Magnocellular neuropeptidergic neurons in hypothalamus: Increases in membrane apposition and number of specialized synapses from pregnancy to lactation. Brain Research Bulletin. 1982; 8(2): 197-204.

106. Theodosis DT, Chapman DB, Montagnese C, Poulain DA, Morris JF. Structural Plasticity in the Hypothalamic Nucleus At Lactation Affects But Not Vasopressin-Secreting. Neuroscience. 1986; 17(3): 661-78.

107. Oliet SHR, Piet R, Poulain DA. Control of glutamate clearance and synaptic efficacy by glial coverage of neurons. Science. 2001; 292(5518): 923-6.

108. Panatier A, Theodosis DT, Mothet JP, Touquet B, Pollegioni L, Poulain DA, Oliet SHR. GliaDerived d-Serine Controls NMDA Receptor Activity and Synaptic Memory. Cell. 2006; 125(4): 775-84.

109. Catheline G, Touquet B, Lombard MC, Poulain DA, Theodosis DT. A study of the role of neuro-glial remodeling in the oxytocin system at lactation. Neuroscience. 2006; 137(1): 309-16.

110. Brownstein M, Russel T, Gainer H. Synthesis, transport and release of posterior pituitary hormones. Science. 1980; 207373-8.

111. Gouzènes L, Desarménien MG, Hussy N, Richard P, Moos FC. Vasopressin regularizes the phasic firing pattern of rat hypothalamic magnocellular vasopressin neurons. The Journal of Neuroscience. 1998; 18(5): 1879-85.

This article is protected by copyright. All rights reserved. 
112. Poulain DA, Wakerley JB. Electrophysiology of hypothalamic magnocellular neurones secreting oxytocin and vasopressin. Neuroscience. 1982; 7(4): 773-808.

113. Wakerley JB, Poulain DA, Brown D. Comparison of firing patterns in oxytocin- and vasopressin-releasing neurones during progressive dehydration. Brain Research. 1978; 148(2): 42540.

114. Elgot A, Hiba OE, Gamrani H. Structural and neurochemical plasticity in both supraoptic and paraventricular nuclei of hypothalamus of a desert rodent Meriones Shawi after a severe dehydration versus opposite treatment by rehydration: GFAP and vasopressin immunohistochemical study. Neuroscience Letters. 2012; 515(1): 55-60.

115. Hawrylak N, Boone D, Salm AK. The surface density of glial fibrillary acidic protein immunopositive astrocytic processes in the rat supraoptic nucleus is reversibly altered by dehydration and rehydration. Neuroscience Letters. 1999; 277(1): 57-60.

116. Hawrylak N, Fleming JC, Salm AK. Dehydration and rehydration selectively and reversibly alter glial fibrillary acidic protein immunoreactivity in the rat supraoptic nucleus and subjacent glial limitans. Glia. 1998; 22(3): 260-71.

117. Latzkovits L, Cserr HF, Park JT, Patlak CS, Pettigrew KD, Rimanoczy A. Effects of arginine vasopressin and atriopeptin on glial cell volume measured as 3-MG space. American Journal of Physiology-Cell physiology. 1993; 33603-8.

118. Sarfaraz D, Fraser CL. rapid communication Effects of arginine vasopressin on cell volume regulation in brain astrocyte in culture. American Journal of Physiology-Endocrinology and Metabolism. 1999; 276E596-E601.

119. Ludwig M, Johnstone LE, Neumann I, Landgraf R, Russell JA. Direct hypertonic stimulation of the rat supraoptic nucleus increases c-fos expressionin glial cells rather than magnocellular neurones. Cell Tissue Research. 1997; 287(1): 79-90.

120. Yuan H, Gao B, Duan L, Jiang S, Cao R, Xiong Y-F, Rao Z-R. Acute hyperosmotic stimulusinduced Fos expression in neurons depends on activation of astrocytes in the supraoptic nucleus of rats. Journal of Neuroscience Research. 2009; 88(6): NA-NA.

121. Jurzak M, Muller AR, Gerstberger R. Characterization of vasopressin receptors in cultured cells derived from the region of rat brain circumventricular organs. Neuroscience. 1995; 65(4): 114559.

122. Syed N, Martens CA, Hsu WH. Arginine vasopressin increases glutamate release and intracellular $\mathrm{Ca} 2+$ concentration in hippocampal and cortical astrocytes through two distinct receptors. Journal of Neurochemistry. 2007; 103229-37.

123. Chen Y, Zhao Z, Hertz L. Vasopressin increases [Ca2+]i in differentiated astrocytes by activation of V1b/V3 receptors but has no effect in mature cortical neurons. Journal of Neuroscience Research. 2000; 60(6): 761-6.

124. Yamagata K, Takahashi N, Akita N, Nabika T. Arginine vasopressin altered the expression of monocarboxylate transporters in cultured astrocytes isolated from stroke-prone spontaneously hypertensive rats and congenic SHRpch1_18 rats. Journal of Neuroinflammation. 2017; 14(1): 176-.

125. Hussy N, Brès V, Rochette M, Duvoid A, Alonso G, Dayanithi G, Moos FC. Osmoregulation of vasopressin secretion via activation of neurohypophysial nerve terminals glycine receptors by glial taurine. The Journal of neuroscience : the official journal of the Society for Neuroscience. 2001; 21(18): 7110-6.

126. Hussy N, Deleuze C, Desarménien MG, Moos FC. Osmotic regulation of neuronal activity: a new role for taurine and glial cells in a hypothalamic neuroendocrine structure. Progress in Neurobiology. 2000; 62(2): 113-34.

127. Deleuze C, Duvoid A, Hussy N. Properties and glial origin of osmotic-dependent release of taurine from the rat supraoptic nucleus. The Journal of physiology. 1998; 507 ( Pt 2)(Pt 2): 463-71.

128. Di S, Popescu IR, Tasker JG. Glial control of endocannabinoid heterosynaptic modulation in hypothalamic magnocellular neuroendocrine cells. J Neurosci. 2013; 33(46): 18331-42.

This article is protected by copyright. All rights reserved. 
129. Haam J, Halmos KC, Di S, Tasker JG. Nutritional state-dependent ghrelin activation of vasopressin neurons via retrograde trans-neuronal-glial stimulation of excitatory GABA circuits. J Neurosci. 2014; 34(18): 6201-13.

130. Windle RJ, Forsling ML, Smith CP, Balment RJ. Patterns of neurohypophysial hormone release during dehydration in the rat. Journal of Endocrinology. 1993; 137(2): 311-9.

131. Bains JS, Potyok A, Ferguson AV. Angiotensin II actions in paraventricular nucleus: functional evidence for neurotransmitter role in efferents originating in subfornical organ. Brain Research. 1992; 599(2): 223-9.

132. Sakai K, Agassandian K, Morimoto S, Sinnayah P, Cassell MD, Davisson RL, Sigmund CD. Local production of angiotensin II in the subfornical organ causes elevated drinking. The Journal of Clinical Investigation. 2007; 117(4): 1088-95.

133. Saxena A, Little JT, Nedungadi TP, Cunningham JT. Angiotensin II type 1a receptors in subfornical organ contribute towards chronic intermittent hypoxia-associated sustained increase in mean arterial pressure. American journal of physiology Heart and circulatory physiology. 2015; 308(5): H435-46.

134. Beresford MJ, Fitzsimons JT. Intracerebroventricular angiotensin II-induced thirst and sodium appetite in rat are blocked by the AT1 receptor antagonist, Losartan (DuP 753), but not by the AT2 antagonist, CGP 42112B. Experimental Physiology. 1992; 77(5): 761-4.

135. Gebke E, Müller AR, Jurzak M, Gerstberger R. Angiotensin II-induced calcium signalling in neurons and astrocytes of rat circumventricular organs. Neuroscience. 1998; 85(2): 509-20.

136. Flôr AFL, Alves JLdB, França-Silva MS, Balarini CM, Elias LLK, Ruginsk SG, Antunes-Rodrigues J, Braga VA, Cruz JC. Glial Cells Are Involved in ANG-II-Induced Vasopressin Release and Sodium Intake in Awake Rats. Frontiers in Physiology. 2018; 91-12.

137. Stern JE, Son S, Biancardi VC, Zheng H, Sharma N, Patel KP. Astrocytes Contribute to Angiotensin II Stimulation of Hypothalamic Neuronal Activity and Sympathetic Outflow. Hypertension. 2016; 68(6): 1483-93.

138. Tardy M, Rolland B, Fages C, Caldani M. Astroglial cells: glucocorticoid target cells in the brain. Clin Neuropharmacol. 1984; 7(4): 296-302.

139. Vielkind U, Walencewicz A, Levine JM, Bohn MC. Type II glucocorticoid receptors are expressed in oligodendrocytes and astrocytes. J Neurosci Res. 1990; 27(3): 360-73.

140. Piechota M, Korostynski M, Golda S, Ficek J, Jantas D, Barbara Z, Przewlocki R. Transcriptional signatures of steroid hormones in the striatal neurons and astrocytes. BMC Neurosci. 2017; 18(1): 37.

141. Carter BS, Hamilton DE, Thompson RC. Acute and chronic glucocorticoid treatments regulate astrocyte-enriched mRNAs in multiple brain regions in vivo. Front Neurosci. 2013; 7139.

142. Zeng J, Li M, Xiao Z, Chen Y, Chang Q, Tian H, Jin H, Liu X. Rapid elevation of calcium concentration in cultured dorsal spinal cord astrocytes by corticosterone. Neurochem Res. 2013; 38(2): 382-8.

143. Champeil-Potokar G, Hennebelle M, Latour A, Vancassel S, Denis I. Docosahexaenoic acid (DHA) prevents corticosterone-induced changes in astrocyte morphology and function. J Neurochem. 2016; 136(6): 1155-67.

144. Chatterjee S, Sikdar SK. Corticosterone treatment results in enhanced release of peptidergic vesicles in astrocytes via cytoskeletal rearrangements. Glia. 2013; 61(12): 2050-62.

145. Unemura K, Kume T, Kondo M, Maeda Y, Izumi Y, Akaike A. Glucocorticoids decrease astrocyte numbers by reducing glucocorticoid receptor expression in vitro and in vivo. J Pharmacol Sci. 2012; 119(1): 30-9.

146. Yuan SY, Liu J, Zhou J, Lu W, Zhou HY, Long LH, Hu ZL, Ni L, Wang Y, Chen JG, Wang F. AMPK Mediates Glucocorticoids Stress-Induced Downregulation of the Glucocorticoid Receptor in Cultured Rat Prefrontal Cortical Astrocytes. PLoS One. 2016; 11(8): e0159513.

147. Lou YX, Li J, Wang ZZ, Xia CY, Chen NH. Glucocorticoid receptor activation induces decrease of hippocampal astrocyte number in rats. Psychopharmacology (Berl). 2018; 235(9): 2529-40.

This article is protected by copyright. All rights reserved. 
148. Zhang H, Zhao Y, Wang Z. Chronic corticosterone exposure reduces hippocampal astrocyte structural plasticity and induces hippocampal atrophy in mice. Neurosci Lett. 2015; 59276-81.

149. Luarte A, Cisternas P, Caviedes A, Batiz LF, Lafourcade C, Wyneken U, Henzi R. Astrocytes at the Hub of the Stress Response: Potential Modulation of Neurogenesis by miRNAs in AstrocyteDerived Exosomes. Stem Cells Int. 2017; 20171719050.

150. Oyola MG, Handa RJ. Hypothalamic-pituitary-adrenal and hypothalamic-pituitary-gonadal axes: sex differences in regulation of stress responsivity. Stress. 2017; 20(5): 476-94.

151. Garcia-Caceres C, Lagunas N, Calmarza-Font I, Azcoitia I, Diz-Chaves Y, Garcia-Segura LM, Baquedano E, Frago LM, Argente J, Chowen JA. Gender differences in the long-term effects of chronic prenatal stress on the HPA axis and hypothalamic structure in rats. Psychoneuroendocrinology. 2010; 35(10): 1525-35.

152. Hertz L, Schousboe I, Hertz L, Schousboe A. Receptor expression in primary cultures of neurons or astrocytes. Prog Neuropsychopharmacol Biol Psychiatry. 1984; 8(4-6): 521-7.

153. Gibbs ME, Hutchinson DS, Summers RJ. Role of beta-adrenoceptors in memory consolidation: beta3-adrenoceptors act on glucose uptake and beta2-adrenoceptors on glycogenolysis. Neuropsychopharmacology. 2008; 33(10): 2384-97.

154. Hertz L, Lovatt D, Goldman SA, Nedergaard M. Adrenoceptors in brain: cellular gene expression and effects on astrocytic metabolism and [Ca(2+)]i. Neurochem Int. 2010; 57(4): 411-20.

155. Huang R, Hertz L. Noradrenaline-induced stimulation of glutamine metabolism in primary cultures of astrocytes. J Neurosci Res. 1995; 41(5): 677-83.

156. Gordon GR, Baimoukhametova DV, Hewitt SA, Rajapaksha WR, Fisher TE, Bains JS. Norepinephrine triggers release of glial ATP to increase postsynaptic efficacy. Nat Neurosci. 2005; 8(8): 1078-86.

157. O'Donnell J, Zeppenfeld D, McConnell E, Pena S, Nedergaard M. Norepinephrine: a neuromodulator that boosts the function of multiple cell types to optimize CNS performance. Neurochem Res. 2012; 37(11): 2496-512.

158. Pearson-Leary J, Osborne DM, McNay EC. Role of Glia in Stress-Induced Enhancement and Impairment of Memory. Front Integr Neurosci. 2015; 963.

159. Golombek DA, Rosenstein RE. Physiology of circadian entrainment. Physiol Rev. 2010; 90(3): 1063-102.

160. Stokkan KA, Yamazaki S, Tei H, Sakaki Y, Menaker M. Entrainment of the circadian clock in the liver by feeding. Science. 2001; 291(5503): 490-3.

161. Buhr ED, Takahashi JS. Molecular components of the Mammalian circadian clock. Handb Exp Pharmacol. 2013(217): 3-27.

162. Takahashi JS, Hong HK, Ko CH, McDearmon EL. The genetics of mammalian circadian order and disorder: implications for physiology and disease. Nat Rev Genet. 2008; 9(10): 764-75.

163. Canal MM, Mohammed NM, Rodríguez JJ. Early programming of astrocyte organization in the mouse suprachiasmatic nuclei by light. Chronobiol Int. 2009; 26(8): 1545-58.

164. Cambras T, López L, Arias JL, Díez-Noguera A. Quantitative changes in neuronal and glial cells in the suprachiasmatic nucleus as a function of the lighting conditions during weaning. Brain Res Dev Brain Res. 2005; 157(1): 27-33.

165. Corvetti L, Aztiria E, Domenici L. Reduction of GFAP induced by long dark rearing is not restricted to visual cortex. Brain Res. 2006; 1067(1): 146-53.

166. Lavialle M, Begue A, Papillon C, Vilaplana J. Modifications of retinal afferent activity induce changes in astroglial plasticity in the hamster circadian clock. Glia. 2001; 34(2): 88-100.

167. Marpegan L, Krall TJ, Herzog ED. Vasoactive intestinal polypeptide entrains circadian rhythms in astrocytes. J Biol Rhythms. 2009; 24(2): 135-43.

168. Becquet D, Girardet C, Guillaumond F, François-Bellan AM, Bosler O. Ultrastructural plasticity in the rat suprachiasmatic nucleus. Possible involvement in clock entrainment. Glia. 2008; 56(3): 294-305.

This article is protected by copyright. All rights reserved. 
169. Barca-Mayo O, Pons-Espinal M, Follert P, Armirotti A, Berdondini L, De Pietri Tonelli D. Astrocyte deletion of Bmal1 alters daily locomotor activity and cognitive functions via GABA signalling. Nat Commun. 2017; 814336.

170. Tso CF, Simon T, Greenlaw AC, Puri T, Mieda M, Herzog ED. Astrocytes Regulate Daily Rhythms in the Suprachiasmatic Nucleus and Behavior. Curr Biol. 2017; 27(7): 1055-61.

171. Brancaccio M, Patton AP, Chesham JE, Maywood ES, Hastings MH. Astrocytes Control Circadian Timekeeping in the Suprachiasmatic Nucleus via Glutamatergic Signaling. Neuron. 2017; 93(6): 1420-35 e5.

172. Abrahamson EE, Moore RY. Suprachiasmatic nucleus in the mouse: retinal innervation, intrinsic organization and efferent projections. Brain Res. 2001; 916(1-2): 172-91.

173. Itri J, Colwell CS. Regulation of inhibitory synaptic transmission by vasoactive intestinal peptide (VIP) in the mouse suprachiasmatic nucleus. J Neurophysiol. 2003; 90(3): 1589-97.

174. Leone MJ, Beaule C, Marpegan L, Simon T, Herzog ED, Golombek DA. Glial and lightdependent glutamate metabolism in the suprachiasmatic nuclei. Chronobiol Int. 2015; 32(4): 573-8.

175. Beaulé C, Swanstrom A, Leone MJ, Herzog ED. Circadian modulation of gene expression, but not glutamate uptake, in mouse and rat cortical astrocytes. PLoS One. 2009; 4(10): e7476.

176. Brancaccio M, Edwards MD, Patton AP, Smyllie NJ, Chesham JE, Maywood ES, Hastings MH. Cell-autonomous clock of astrocytes drives circadian behavior in mammals. Science. 2019; 363(6423): 187-92.

This article is protected by copyright. All rights reserved. 

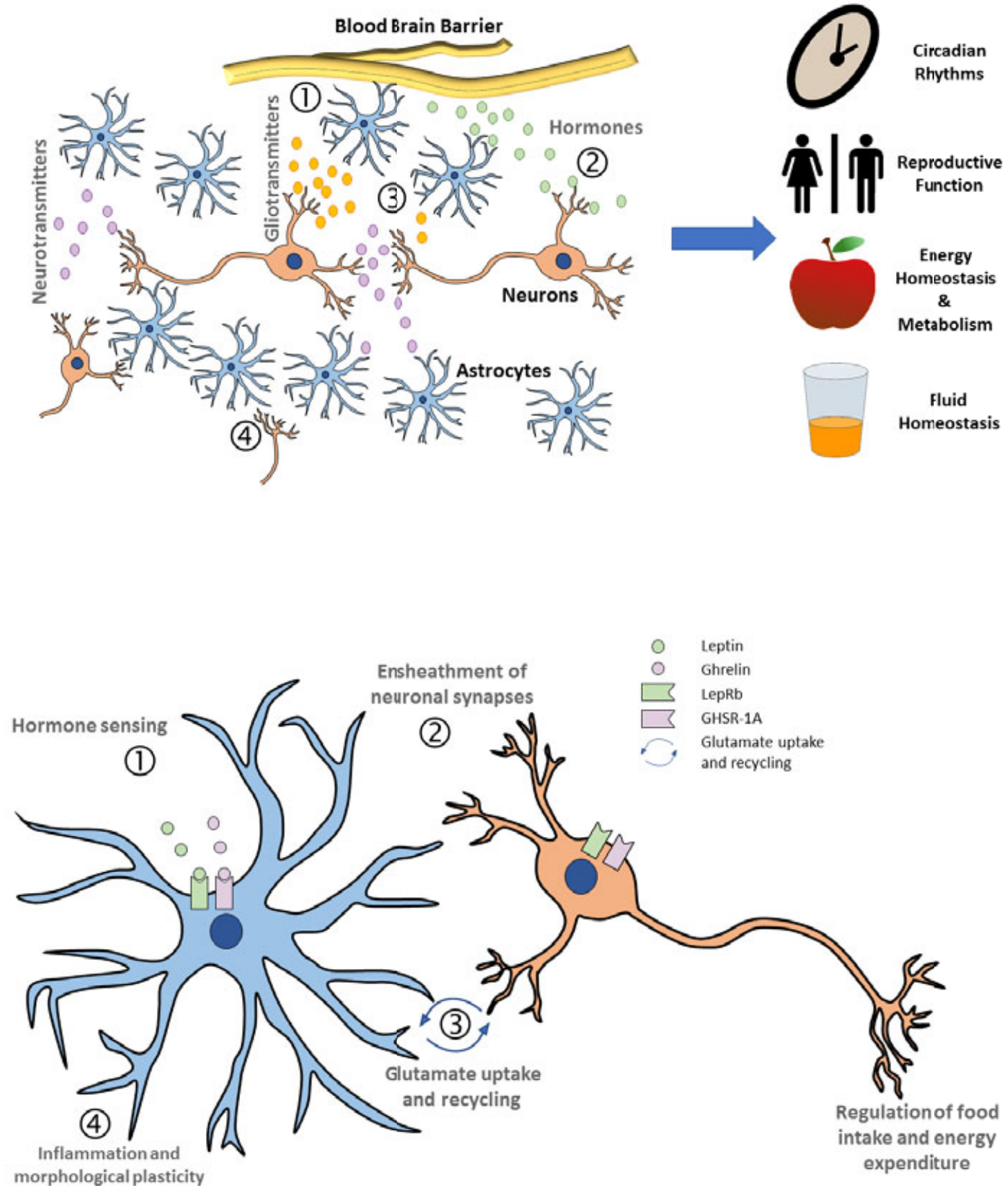

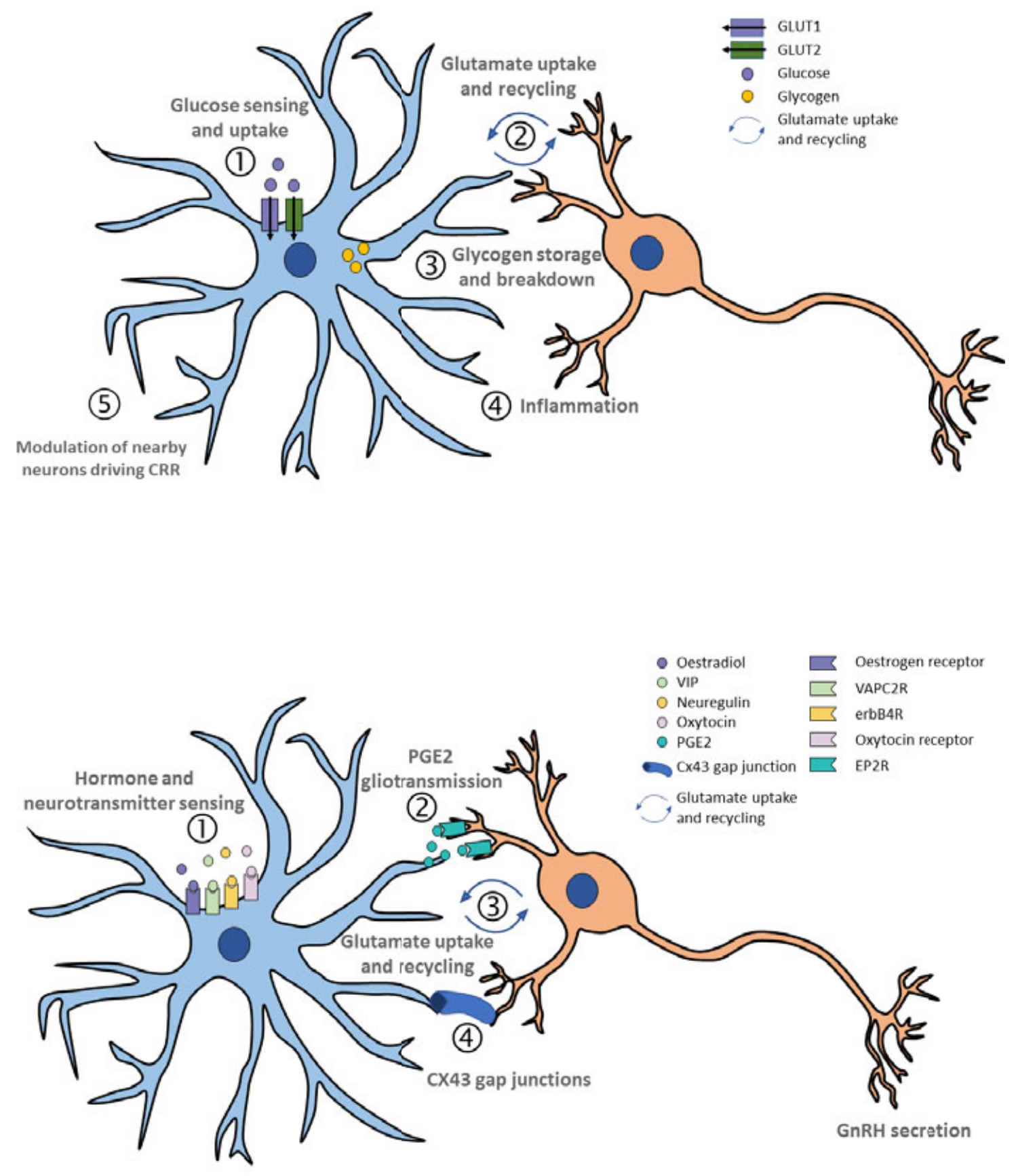

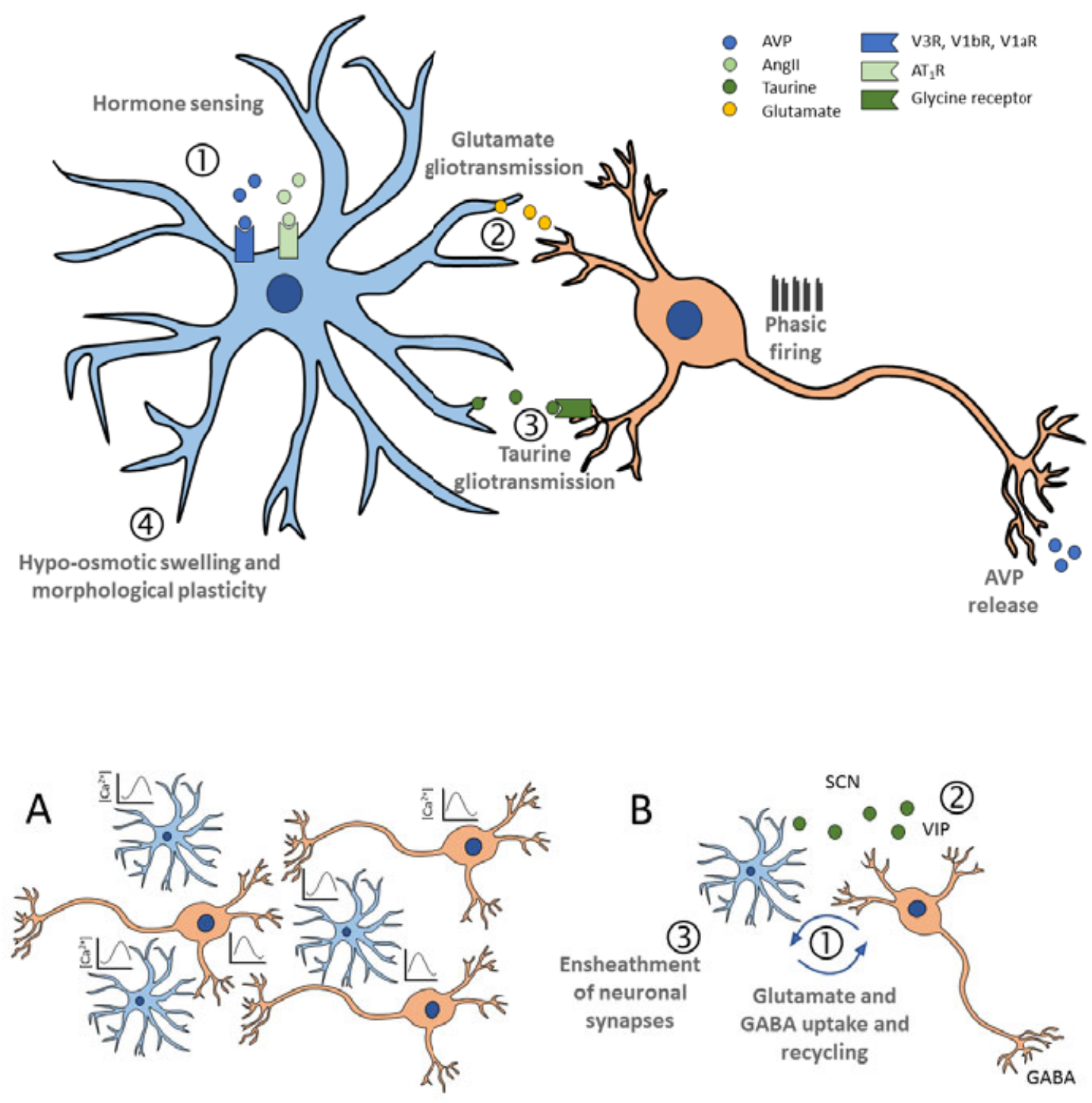